\title{
Leading Tip Drives Soma Translocation via Forward F-Actin Flow during Neuronal Migration
}

\author{
Min He, ${ }^{1,2}$ Zheng-hong Zhang, ${ }^{1}$ Chen-bing Guan, ${ }^{1}$ Di Xia, ${ }^{1}$ and Xiao-bing Yuan ${ }^{1}$ \\ ${ }^{1}$ Institute of Neuroscience and State Key Laboratory of Neuroscience, Shanghai Institutes for Biological Sciences, Chinese Academy of Sciences, Shanghai \\ 200031, China, and ${ }^{2}$ Graduate School of the Chinese Academy of Sciences, Shanghai 200031, China
}

Neuronal migration involves coordinated extension of the leading process and translocation of the soma, but the relative contribution of different subcellular regions, including the leading process and cell rear, in driving soma translocation remains unclear. By local manipulation of cytoskeletal components in restricted regions of cultured neurons, we examined the molecular machinery underlying the generation of traction force for soma translocation during neuronal migration. In actively migrating cerebellar granule cells in culture, a growth cone (GC)-like structure at the leading tip exhibits high dynamics, and severing the tip or disrupting its dynamics suppressed soma translocation within minutes. Soma translocation was also suppressed by local disruption of F-actin along the leading process but not at the soma, whereas disrupting microtubules along the leading process or at the soma accelerated soma translocation. Fluorescent speckle microscopy using GFP- $\alpha$-actinin showed that a forward F-actin flow along the leading process correlated with and was required for soma translocation, and such F-actin flow depended on myosin II activity. In migrating neurons, myosin II activity was high at the leading tip but low at the soma, and increasing or decreasing this front-to-rear difference accelerated or impeded soma advance. Thus, the tip of the leading process actively pulls the soma forward during neuronal migration through a myosin II-dependent forward F-actin flow along the leading process.

\section{Introduction}

Neuronal migration encompasses three successive steps- the extension of the leading process, nuclear movement and soma translocation, and the retraction of the trailing process (Edmondson and Hatten, 1987; Komuro and Rakic, 1995; Lauffenburger and Horwitz, 1996; Walsh and Goffinet, 2000; Ridley et al., 2003). The leading process of migrating neurons exhibits a dynamic growth cone (GC)-like structure at its tip, which actively extends lamellipodia and filopodia in a manner similar to that found at axonal GCs (Ono et al., 1997; Komuro et al., 2001; Lambert de Rouvroit and Goffinet, 2001; Polleux et al., 2002; Yacubova and Komuro, 2002; Guan et al., 2007). In growing axons, interaction between GC and the substrate, together with F-actin retrograde flow powered by myosin II activity and F-actin polymerization, propels the axon extension (Suter and Forscher, 2000; Lowery and Van Vactor, 2009). In addition to sensing guidance cues, axonal GCs are also known to generate tension that pulls the neurite forward, as indicated by the measurable traction force at GC surface and along the neurite shaft (Bray, 1979; Letourneau et al., 1987; Lamoureux et al., 1989; Heidemann and Buxbaum, 1990; Moore et al., 2009). During neuronal migration, the tip of the leading

Received Jan. 15, 2010; revised June 1, 2010; accepted June 25, 2010

This work was supported by 973 projects $(2006$ CB806600, 2006C B943903) and grants from the National Natural Science Foundation of China (30625023, 30721004) and Chinese Academy of Sciences (KSCX2-YW-R-103). We thank M-m. Poo for comments on the manuscript, $Q$. Hu for support in confocal microscopy, Y. Fu for aid in data analysis, and J.-Y. Yu for support in cell culture.

The authors declare that they have no competing financial interests.

Correspondence should be addressed to Xiao-bing Yuan at the above address. E-mail: yuanxb@ion.ac.cn.

DOI:10.1523/JNEUROSCI.0240-10.2010

Copyright $\odot 2010$ the authors $\quad 0270-6474 / 10 / 3010885-14 \$ 15.00 / 0$ process and the soma exhibit coordinated motility (Bellion et al., 2005; Guan et al., 2007), but whether the traction force generated at the tip of the leading process directly contributes to soma translocation remains unclear.

Both F-actin and microtubules play important roles in the control of cell morphology and motility (Fletcher and Mullins, 2010). In migrating neurons, the leading process is filled with thick microtubule bundles, whereas the nucleus at the soma is surrounded by cage-like microtubule network (Rivas and Hatten, 1995). Motor proteins associated with these microtubules play important roles in the nucleokinesis during neuronal migration (Bellion et al., 2005; Schaar and McConnell, 2005; Tsai and Gleeson, 2005; Tsai et al., 2007; Vallee et al., 2009). On the other hand, ultrastructural study of developing cerebellum showed that microtubules in the leading process of migrating granule cells are polarized, with the plus end pointing to the distal end of the leading process (Rakic et al., 1996). Based on these observations, it has been suggested that microtubule bundles in the leading process may restrain the nuclear translocation, which occurs upon the depolymerization of those oriented microtubules at the minus end (Rakic et al., 1996).

Studies in cultured cerebellar granule cells showed that F-actin is enriched in the leading process of migrating neurons (Rivas and Hatten, 1995) and pharmacological perturbation of either F-actin or its associated motor protein myosin II halted the migration of cultured neurons (Rivas and Hatten, 1995; Bellion et al., 2005; Schaar and McConnell, 2005; Tsai and Gleeson, 2005; Tsai et al., 2007; Vallee et al., 2009). In addition to the well known function in driving the leading edge protrusion, myosin II is considered to promote nucleokinesis by producing contraction at the 
cell rear (Bellion et al., 2005; Schaar and McConnell, 2005; Tsai et al., 2007; Yam et al., 2007; Vallee et al., 2009). However, a recent study showed that during glia-supported migration of cerebellar granule cells, the majority of actomyosin is located in front of the nucleus rather than in the trailing end, and may "pull" the soma forward (Solecki et al., 2009). Migration of these neurons is associated with a forward F-actin flow in the proximal leading process. Global inhibition of F-actin dynamics and myosin II activity by uniform application of pharmacological agents prevented the coordinated advance of centrosome and neuronal soma and stopped the forward F-actin flow in the proximal leading process (Solecki et al., 2009). However, this study of using global inhibition is insufficient to distinguish the relative contribution of different subcellular regions, in particular the leading tip versus proximal neurite shaft or the cell rear, in driving soma translocation. Moreover, how the direction of F-actin flow in migrating neuron is determined remains unclear. Since cortical F-actin is known to flow toward the region with higher myosin contractility in the cell (White and Borisy, 1983; Bray and White, 1988; Benink et al., 2000; Munro et al., 2004), a forward F-actin flow in the leading process suggests a higher myosin II activity at the distal rather than the proximal leading process. Overall, it remains unclear how the myosin II-dependent driving force is generated and exerted on the soma during neuronal migration.

In cultured cerebellar granule cells, we examined the potential role of the distal leading process, particularly the GC-like structure at the leading tip, in driving soma translocation. We manipulated the cytoskeleton dynamics and myosin II activity at restricted regions of migrating neurons by local rather than global perfusion with pharmacological agents. We also examined the role of F-actin flow along the entire leading process in soma translocation. We found that the GC-like structure at the leading tip may serve an active role in pulling the soma forward during neuronal migration through a myosin II-dependent forward flow of F-actin along the leading process.

\section{Materials and Methods}

Animals. All newborn Sprague Dawley (SD) rats used in the present study were provided by Shanghai SLAC Laboratory Animal. All experimental procedures involving rats were performed under the guideline and permission of the Bioethics Committee of the Institute of Neuroscience at the Shanghai Institutes for Biological Sciences, Chinese Academy of Sciences (NA-060410, NA-100410-2).

Primary culture of cerebellar granule cells. Dissociated culture of cerebellar granule cells were performed as previously described with some modifications (Ding et al., 2007; Guan et al., 2007). Briefly, the cerebellum cortex was dissected on ice from $\mathrm{P} 0-\mathrm{P} 1 \mathrm{SD}$ rats, digested with $0.125 \%$ trypsin for $7-9 \mathrm{~min}$ at $37^{\circ} \mathrm{C}$, and dissociated into single cells by gentle trituration. Cells were plated on cover glass coated with $100 \mu \mathrm{g} / \mathrm{ml}$ poly-D-lysine and $25 \mu \mathrm{g} / \mathrm{ml} \mathrm{laminin}$ at a low density $\left(1-2 \times 10^{5}\right.$ cells per $18 \times 18 \mathrm{~mm}$ cover glass) in Neurobasal medium (Invitrogen) supplemented with 10\% fetal bovine serum (PAA) and 2\% B27 (Invitrogen). For neuronal transfection, dissociated cells were electroporated with 1-3 $\mu \mathrm{g}$ of DNA constructs using the Rat Neuron Nucleofector Kit (Amaxa Biosystems) according to the manufacturer's instructions (Li et al., 2005; Guan et al., 2007).

Neuronal migration assay. Cultures of neurons were transferred into a homemade heat chamber under the phase-contrast microscope (CK-40, Olympus), and L-15 medium (Invitrogen) was used during the observation. Neurons with leading process length of $\sim 50-100 \mu \mathrm{m}$, a typical fan-like tip structure, spindle-shape cell body, and thin trailing process were assayed for their migratory behavior. Time-lapse images were captured using a CCD (charge-coupled device) camera (TKC1381; JVC) attached to the microscope. For measurement of soma translocation, the soma center position was determined by the midpoint of the front point and rear point of the soma. The distances of soma center translocation along the migration trajectory were measured using the software ImageJ (supplemental Fig. $1 \mathrm{~A}$, available at www.jneurosci.org as supplemental material). To ensure that the observed movement of soma center was not caused by the morphological change of the soma, only neurons with both the front point and the rear point moved forward and a net translocation of soma center of $>4$ pixels over the $10 \mathrm{~min}$ imaging period $(\sim 0.1 \mu \mathrm{m} /$ $\mathrm{min}$ ) were considered as migratory neurons and were further assayed for their responses to different agents (supplemental Fig. $1 B$, available at www.jneurosci.org as supplemental material). To analyze the dynamics of the GC-like structure at the leading tip, contours of the tip structure and membrane ruffles were traced using the software Image-Pro Plus 6.0, and the total length of tip perimeters, total tip areas, and the area that ruffles covered were calculated by the software.

Immunocytochemistry and confocal microscopy. Neurons were plated on gridded cover glass. Migratory behavior of selected neurons was monitored by time-lapse imaging, and their position on the gridded cover glass was marked. After immunostaining, the monitored neuron was picked out according to its location. Optical sections in $z$-series were scanned at $0.2 \mu \mathrm{m}$ intervals using a confocal microscope (A1R, Nikon) with a $60 \times, 1.4 \mathrm{NA}$ oil objective. $Z$-stack images were then generated by maximal projection.

For cytoskeleton staining, cultured neurons were fixed at $37^{\circ} \mathrm{C}$ with simultaneous membrane extraction by a fixative containing $2 \%$ glutaraldehyde and $0.3 \%$ Triton-100 in PHEM buffer, pH 7.0. After blocking with $5 \%$ BSA, cells were incubated with mouse anti- $\alpha$-tubulin (monoclonal, 1:2000, Sigma-Aldrich) and phalloidin (1:45, Invitrogen) overnight at $4{ }^{\circ} \mathrm{C}$, followed by rinse in PBS and 20 min incubation of anti-mouse secondary antibody (1:1000, Invitrogen) at room temperature. The nucleus was counterstained by TOTO-3 (1:1000, Invitrogen). To visualize the cytoskeleton organization inside the neuron, line scan along the neuron was performed and straightened to generate the $y z$ optic section.

To assay the phosphorylated myosin regulatory light chain (p-MLC, at serine-19) in neurons, cultures were fixed at $37^{\circ} \mathrm{C}$ with $4 \%$ paraformaldehyde. The primary antibody used was anti-p-MLC (polyclonal, 1:50, Cell Signaling Technology). Specificity of this immunostaining was validated by analyzing the staining signal after pharmacological interference of endogenous p-MLC level. As shown in supplemental Figure 7 (available at www.jneurosci.org as supplemental material), average immunostaining signal for p-MLC in neurons was significantly reduced after incubation with the Rho kinase inhibitor Y-27632 (25 $\mu \mathrm{M}$ in bath), and elevated by the myosin light chain phosphatase inhibitor calyculin A (Caly, $1 \mathrm{~nm}$ in bath). However, application of blebbistatin (Bleb, $50 \mu \mathrm{M}$ in bath), which inhibits myosin II activity by specifically interferes with the myosin ATPase activity (Kovács et al., 2004), did not cause significant changes in the p-MLC signal. When analyzing p-MLC signals in migrating and nonmigrating neurons, cells were costained by CY3-Bis NHS Ester $(0.05 \mathrm{mg} / \mathrm{ml}$, GE Healthcare), which labels total proteins to eliminate the cell volume effect. Normalized p-MLC signal ( $\mathrm{p}$-MLC/CY3-Bis NHS Ester) was coded by pseudocolors (0-2) in ratio images.

Local perfusion and local application of drugs. Local perfusion of pharmacological agents was performed as described previously with modifications (Zheng et al., 1994). Briefly, injection and suction pipette were placed using a pair of manipulators at two sides of the neuron, in a direction nearly perpendicular to the leading process of the migrating neuron, with a perpendicular distance of about $50-75 \mu \mathrm{m}$ and $40-50$ $\mu \mathrm{m}$ away from the neuron for the injection and suction pipette, respectively. The diameters of the tip opening for the injection and suction pipette were about $1 \mu \mathrm{m}$ and $8-12 \mu \mathrm{m}$, respectively. Drug solution was injected into culture medium by repetitive pulses of air pressure ( 3 psi, 20 ms duration) at a frequency of $2 \mathrm{~Hz}$. Reuptake of the drug solution was controlled by a pump at a speed of $\sim 25 \mu \mathrm{l} / \mathrm{min}$. Restricted region of the cell was exposed to the liquid flow, as indicated by the ink perfusion shown in supplemental Figure $2 B$ (available at www.jneurosci.org as supplemental material). Fluorescent staining after $20 \mathrm{~min}$ local perfusion of the F-actin depolymerizing agent latrunculin A (LA, $100 \mu \mathrm{M}$ in the pipette) in middle of the leading process showed restricted disruption of F-actin within the perfused region $(\sim 30 \mu \mathrm{m}$ wide) (supplemental Fig. 
$2 B$, available at www.jneurosci.org as supplemental material) at the neurite shaft, in contrast to the global disruption of F-actin inside the cell after bath application of the same agent ( $1 \mu \mathrm{M}$ in bath) (supplemental Fig. $2 \mathrm{~A}$, available at www.jneurosci.org as supplemental material). Local application of chemical gradient was performed by placing one micropipette with $\sim 1 \mu \mathrm{m}$ tip opening at a distance of $\sim 50-75 \mu \mathrm{m}$ from the leading tip or rear end of the soma, with repetitive puffing as mentioned above. Based on previous fluorescent measurements, the concentration of chemicals reaching the leading tip or soma is $\sim 100$ times lower than the chemical concentration in the puffing pipette (Lohof et al., 1992).

Fluorescent live imaging. Dissociated neurons were transfected with plasmids encoding GFP- $\alpha$-actinin $(3 \mu \mathrm{g} / \mathrm{ml}$ ) by electroporation (Amaxa) before plating. The culture was transferred into an incubator attached to the confocal microscope (FV1000, Olympus). Time-lapse fluorescent images were acquired every $10 \mathrm{~s}$ using a $60 \times, 1.42 \mathrm{NA}$ oil lens and focus drift was prevented by using an automatic focus drift compensation system (IX2-ZDC). Line scans were performed and kymographs were generated in time-lapse images by using Image-Pro Plus 6.0 and ImageJ. A line was drawn along the migratory trajectory or along the filopodia of the GC-like structure at the leading tip with line width of 10 pixels $(\sim 1.4$ $\mu \mathrm{m}$ ) to cover the width of the neurite. Kymographs were derived without background subtraction after line straightening. The slopes of traces of fluorescent speckles were measured in the kymograph and averaged to indicate the speed of F-actin flow.

Laser ablation of the leading tip. Neurons were transfected with EGFP and incubated under Nikon confocal microscope (A1, 60×, $1.4 \mathrm{NA}$ objective) equipped with two-photon laser scanner. Neurons with typical bipolar morphology and GFP-fluorescence were first monitored for their migratory behavior, and actively migrating neurons were selected for further experiment. Ablation was performed by $10-15$ iterations of twophoton laser microbeam ( $800 \mathrm{~nm}, 50 \%$ laser power) at the base of GClike structure of the leading process or at the trailing process. Successful severing of the neurite was verified by the transient leakage of GFP proteins from the severing site and merely shrinkage of the severed neurite but not the unsevered neurite. Images were acquired every $1 \mathrm{~min}$ before and after neurite severing, and neurons with successful severing were included in the migration analysis.

Sources and preparation of reagents. Cytochalasin D (CD), LA, nocodazole (Noc), tautomycin (Tau), and Y-27632 were from Calbiochem; jasplakinolide (Jasp) was from Invitrogen; Bleb and 2,3-butanedione monoxime (BDM) were from Sigma-Aldrich; paclitaxel (Taxol) was from Tocris Bioscience; Caly was from Millipore, and concanavalin A (Con A) was from Invitrogen. Pharmacological agents were dissolved in DMSO or PBS in $100 \times$ stock solution, and diluted in PBS before use.

Statistical analysis. In neuronal migration assay, the relative speed of soma translocation under various treatments was calculated as the ratio of the speed after drug application to the speed of the same neuron before drug application (after/before). Data were presented as mean \pm SEM. Statistical analysis was performed using the software SAS (Statistical Analysis System) 6.12 and SPSS (Statistical Package for Social Science) 11.0. Both Student's $t$ test and Kolmogorov-Smirnov test were used to analyze the statistical significance. Student's $t$ test was used to compare the average level of normalized p-MLC signal between migrating and nonmigrating neurons. For analyzing the distribution of $\mathrm{p}$-MLC within the neuron, the average signals of p-MLC in the leading tip, neurite shaft, and soma of each neuron were calculated and analyzed by Student's $t$ test.

\section{Results}

\section{Dynamics of the leading tip in migrating neurons}

To understand the underlying mechanism of soma translocation during neuronal migration, we first examined the migratory behavior of isolated cerebellar granule cells from postnatal rats (P0-P1) on the surface of glass substratum coated with laminin, using time-lapse video microscopy. This culture method differs from glia-supported migration assay (Edmondson and Hatten, 1987; Solecki et al., 2006, 2009) by the absence of glia-contributed factors and more direct targeting of pharmacological manipulations of neurons. Single isolated granule cells in this culture ex- hibited the typical bipolar morphology with a leading process and a GC-like structure at its advancing tip. As shown in supplemental Figure $1 B$ (available at www.jneurosci.org as supplemental material), $\sim 33 \%$ of observed neurons with the bipolar morphology exhibited net soma translocation $<1 \mu \mathrm{m}$ during the $10 \mathrm{~min}$ time-lapse imaging. In all the following studies, this group of less active neurons was considered as nonmigratory, and the rest of observed neurons were considered to be migratory. We next examined the dynamics of the GC-like structure of the leading process in migrating and nonmigrating neurons of similar fan-like morphology (Fig. 1A,B; supplemental Movies 1, 2, available at www.jneurosci.org as supplemental material). By repetitive tracing the contour of the GC-like structure at an interval of $1 \mathrm{~min}$ and superimposing these contours, we found that the leading tip of migrating neurons exhibited more active morphological changes (Fig. 1A-C). The coefficients of variation (CVs, over 10 min) of the total length of the perimeter and total area of the GC-like structure were much larger in migrating neurons than in nonmigrating neurons (Fig. $1 C$ ), indicating higher tip dynamics in migrating neurons. This was also reflected by more frequently observed large-scale membrane ruffles that flowed from the periphery to the center of the GC-like structure (Fig. $1 B, D$; supplemental Movies S1, S2, available at www.jneurosci.org as supplemental material), as shown by much longer total time with detectable ruffling and the duration of each ruffling activity (assayed over a 10 min duration) (Fig. 1D), as well as higher "ruffling index," which was defined as the ratio of the area covered by the ruffle flow divided by the total area of the GC-like structure (Fig. 1E). Thus, migrating neurons exhibit much higher morphological dynamics than nonmigrating neurons at the leading neurite tip, suggesting the existence of higher F-actin dynamics in this region of migrating neurons.

\section{Dynamics of leading tip is required for soma translocation}

To investigate the potential function of the GC-like structure at the leading process in driving soma translocation, we next examined the effect of severing the tip of the leading process of migrating neurons by two-photon laser microbeam (see Materials and Methods) (O’Brien et al., 2009). We found that in all cases (4/4), soma translocation stopped within a few minutes after the transection of the tip (4/4) (supplemental Fig. 3A-C, available at www.jneurosci.org as supplemental material). In contrast, severing the trailing process either had no obvious effect $(2 / 4)$ or even accelerated (2/4) soma translocation (supplemental Fig. 3D-F, available at www.jneurosci.org as supplemental material). These results suggest that the leading tip is required for soma translocation.

In another approach to disrupt the leading tip, we interfered with tip dynamics by local perfusion of pharmacological agents. Immunostaining of migrating neurons (see Materials and Methods) showed that the GC-like structure at the leading tip is enriched with F-actin, with the fan-like periphery region devoid of microtubules (Fig. 2A). We found that local perfusion with a specific F-actin depolymerizing agent LA (100 $\mu \mathrm{M}$ in the pipette) or $\mathrm{CD}$ ( $50 \mu \mathrm{m}$ in the pipette), using a pair of injection and suction pipettes (see Materials and Methods), led to immediate collapse of the GC-like structure, followed within a few minutes by the inhibition of soma translocation, although the soma was located far away $(>50 \mu \mathrm{m})$ from the perfusion flow (Fig. $2 \mathrm{~B}$ ). In contrast, perfusion with the mock solution $(0.1 \%$ DMSO in the pipette) did not affect the tip morphology or the soma translocation (Fig. 2 B). Furthermore, local perfusion with Jasp (5 $\mu \mathrm{M}$ in the pipette), which stabilizes F-actin (Gallo et al., 2002; 
A

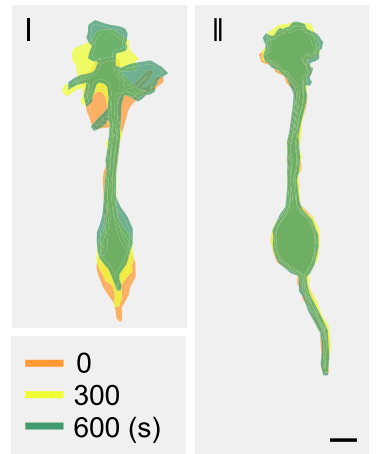

C
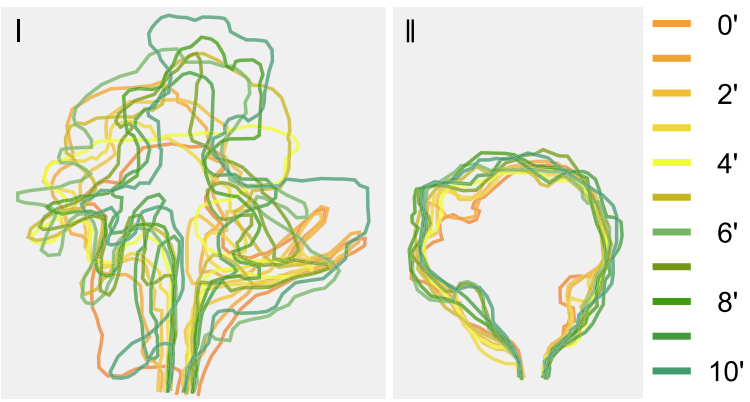

D
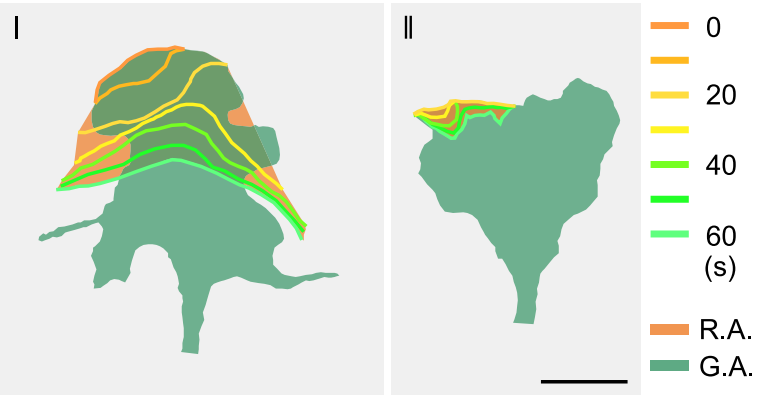

E

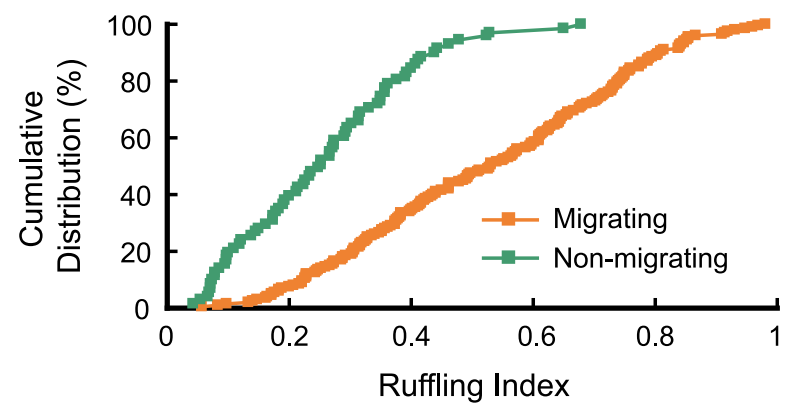

B
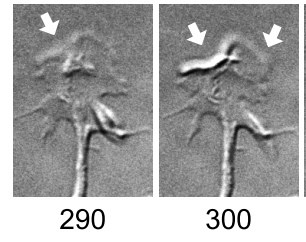
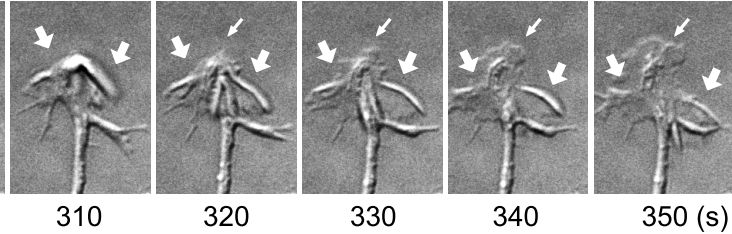

330

340

$350(\mathrm{~s})$
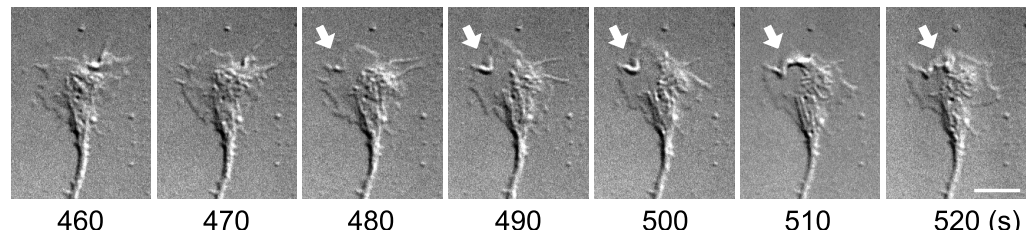

500
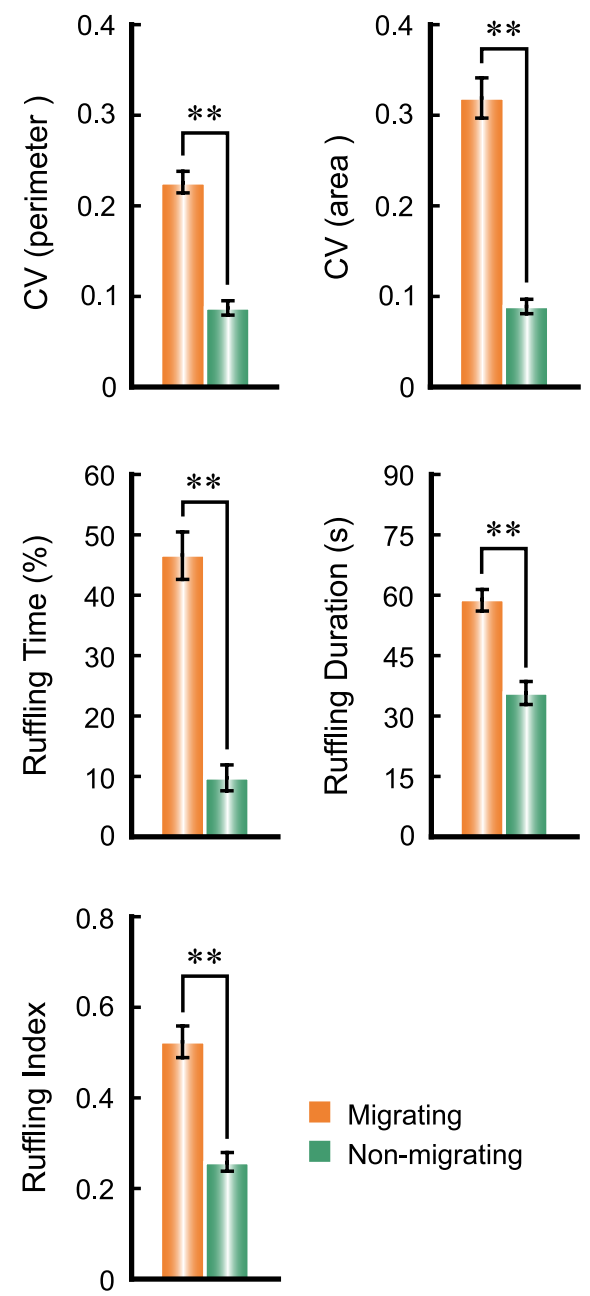

Migrating

Non-migrating

Figure 1. Migrating neurons exhibit higher dynamics of leading tip. The relative position of a migrating neuron (I) and a nonmigrating neuron (II) at indicated time points are shown in pseudocolor images in $\boldsymbol{A}$. Time-lapse images of each GC-like structure (GC) at leading tip over 160 sare shown in $\boldsymbol{B}$ (see also supplemental Movies 1, 2, available at www.jneurosci.org as supplemental material). Thickarrows indicate the membrane ruffles. Thin arrows indicate the extension of the lamellipodia. Contours of GC at different time points were traced from the time-lapse images and superimposed contours with pseudocolors are shown in C (left). CVs of the total length of GC perimeter and CVs of GC area over time for migrating neurons $(n=41)$ and nonmigrating neurons ( $n=44$ ) are shown in the histograms in C (right). Membrane ruffles at the $\mathrm{GC}$ were traced from the time-lapse images and superimposed to indicate the area covered by the ruffle flow ( $\boldsymbol{D}$, orange). Shape of the $\mathrm{GC}$ at the beginning of the ruffling cycle is also shown (green) to indicate the GC area. R.A., Ruffling area; G.A., GCarea. The total time with detectable membrane ruffles during the 10 min imaging and the average duration of each ruffle cycle (from the start at the $\mathrm{GC}$ periphery to the fade out at the central region) are shown in histograms in $\boldsymbol{D}$ (right). Cumulative distributions of ruffling indices (ruffling area/GC area) for ruffles ( $n=194$ and 71 , respectively) observed in migrating and nonmigrating neurons are shown in $\boldsymbol{E}$ (left), and the average indices are shown in the histogram in $\boldsymbol{E}$ (right). ${ }^{* *} p<0.01$, data are significantly different between migrating neurons and nonmigrating neurons (Student's $t$ test in $\boldsymbol{C}$ and $\boldsymbol{D}$, and Kolmogorov-Smirnov test in $\boldsymbol{E}$, respectively). Scale bars, $5 \mu \mathrm{m}$.

Solecki et al., 2009), stopped the dynamics of the GC-like structure without causing its collapse and also inhibited soma translocation (Fig. $2 B$ ). Thus, soma translocation depends on not only the presence but also the dynamics of the leading tip. This re- quirement of tip dynamics was further supported by the finding that disrupting F-actin at the GC-like structure with a frontal gradient of LA (100 $\mu \mathrm{m}$ in the pipette, see Materials and Methods) resulted in the retraction of the leading process and subsequent 
A
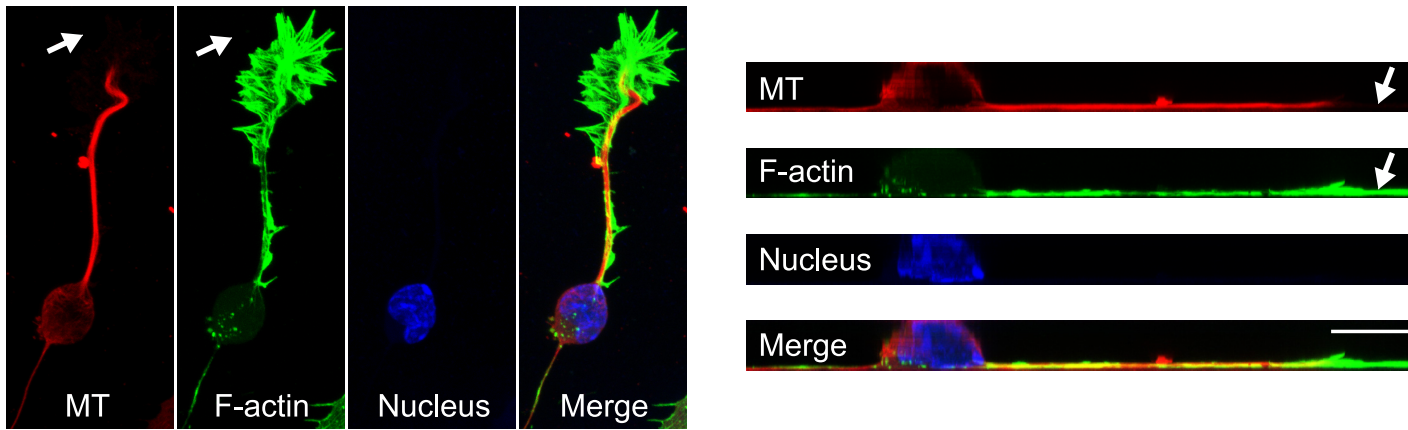

F-actin

\section{Nucleus}

\section{Merge}

B
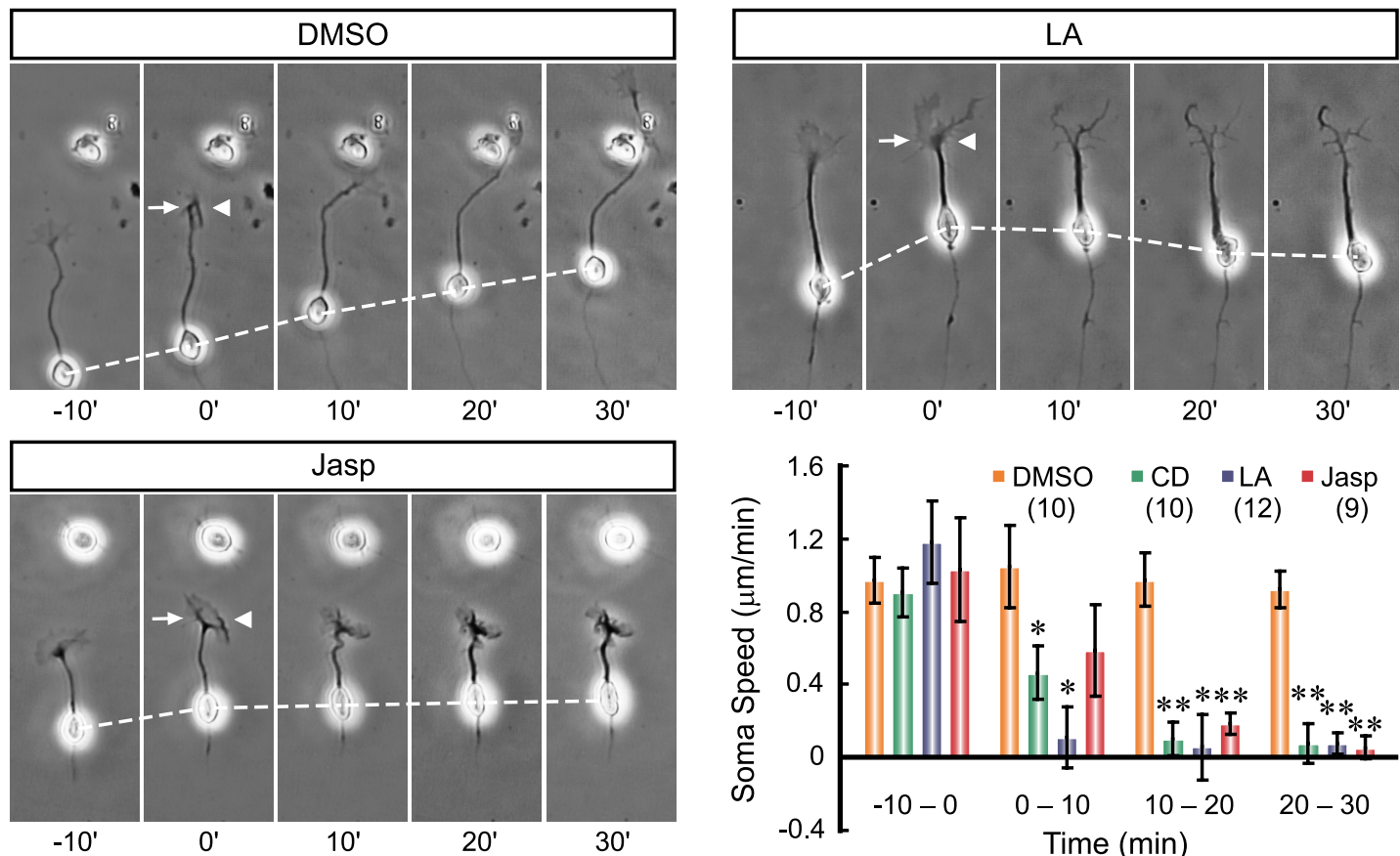

$0^{\prime}$

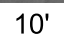

$20^{\prime}$

$30^{\prime}$

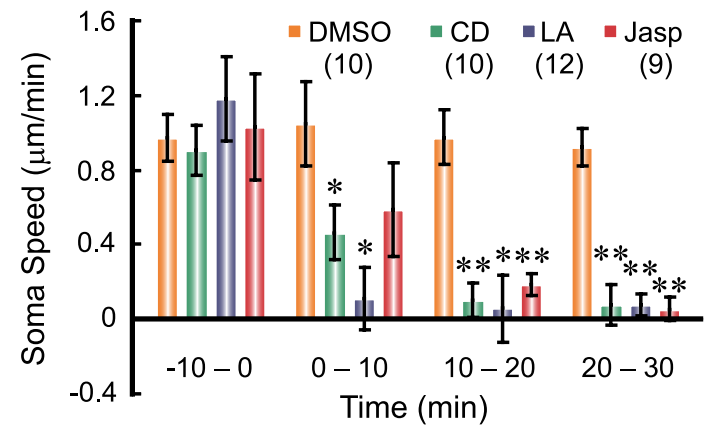

C
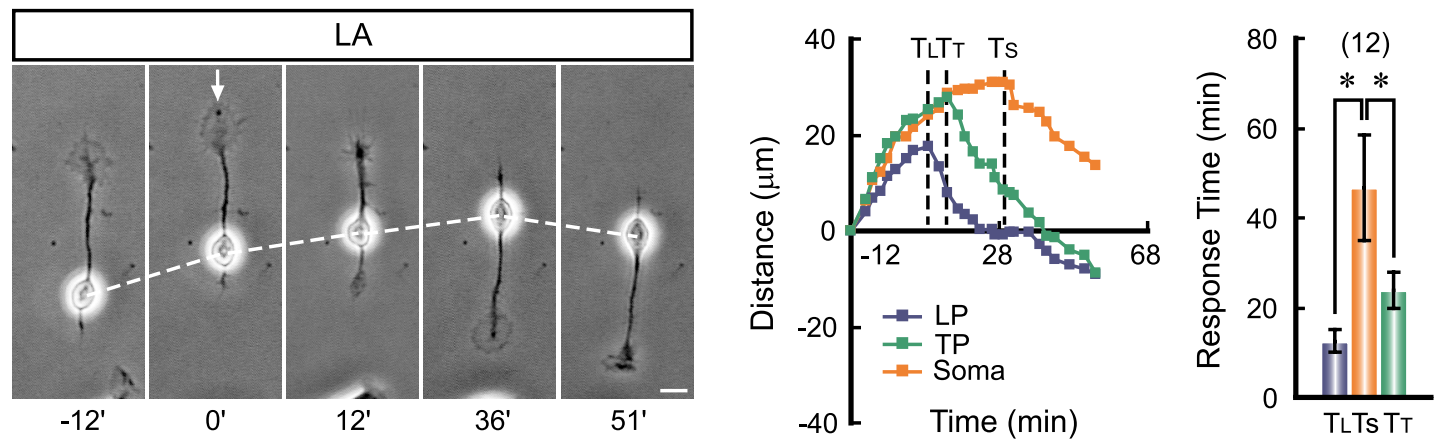

Figure 2. F-actin-dependent dynamics of the leading tip is essential for soma translocation. $A$, Confocal fluorescent images show the distribution of $\mathrm{F}$-actin (green) and microtubules (red) in a migrating neuron (left). Line scan along the neuron was performed and images of the straightened yz optical section are shown for better illustration of cytoskeletal components in sagittal profile of the neuron (right). Note enrichment of F-actin and devoid of microtubules at the periphery region of the GC-like structure (arrows). Different pharmacological agents were locally perfused to the leading tip with a pair of pipettes. Representative images and average soma speed before and after drug application are shown in $\boldsymbol{B}$. The arrow and arrowhead in images indicate direction of the injection and suction pipettes, respectively (see Materials and Methods). Pharmacological agents applied are DMSO (0.1\% in the pipette), LA (100 $\mu \mathrm{M}$ in the pipette), $C D$ (50 $\mu \mathrm{m}$ in the pipette), and Jasp (5 $\mu \mathrm{m}$ in the pipette). Numbers of examined cells for each treatment are shown in brackets. ${ }^{*} p<0.05,{ }^{* *} p<0.01$, significant differences are found between the soma speed before and after the drug application (Student's $t$ test). Time-lapse images in $C$ show the reversal response of a neuron to a frontal gradient of LA (100 $\mu \mathrm{m}$ in the pipette). The net distances of translocation of the soma, leading process (LP), and trailing process (TP) of this neuron at different time points before and after LA application (from $0 \mathrm{~min}$ ) are shown in the curves in the middle. The time points when the LP, TP, and the soma started to reverse their translocation in response to the LA gradient are indicated by three dashed lines and are labeled as $\mathrm{T}_{\mathrm{L}}, \mathrm{T}_{\mathrm{T}}$, and $\mathrm{T}_{\mathrm{S}}$, respectively. Average $\mathrm{T}_{\mathrm{L}^{\prime}} \mathrm{T}_{\mathrm{T}}$, and $\mathrm{T}_{\mathrm{S}}$ from 12 neurons are shown in the histogram at right. Note that an order of $\mathrm{T}_{\mathrm{L}}<\mathrm{T}_{\mathrm{T}}$ $<\mathrm{T}_{\mathrm{S}}$ was consistently observed. Error bars, SEM. Scale bars, $10 \mu \mathrm{m}$. 
formation and extension of the GC-like structure at the trailing end, followed with a delay of $\sim 20 \mathrm{~min}$ by the reversal of soma translocation (Fig. 2C). Together, these results indicate that the leading tip plays an instructive role in soma translocation in these cultured cerebellar granule cells.

\section{Integrity of F-actin along the leading process is required for soma translocation}

In a polarized migrating cell, the driving force for soma translocation may originate from the contraction at the cell rear (Ridley et al., 2003; Bellion et al., 2005; Vallee et al., 2009). For soma translocation of cultured granule cells migrating on glia fibers, the traction force generated by the proximal shaft of the leading process is known to be important (Solecki et al., 2009). Our findings above further indicated that the leading tip may serve an active role in generating the required traction force on the soma. The idea that cytoskeletal components along the leading process may transmit the traction force was further examined by locally disrupting the integrity of F-actin and microtubules with pharmacological agents. We found that perfusion with the F-actin depolymerizing agent LA or $\mathrm{CD}$ in the middle of the leading process did not affect leading tip extension, but rapidly inhibited soma advance (Fig. $3 C, E, F$ ), suggesting that the integrity of F-actin along the leading process is required for soma translocation. In contrast, similar perfusion with F-actin stabilizing agent Jasp in the middle of the leading process had no effect on soma translocation (Fig. $3 E, F$ ), although perfusion at the leading tip inhibited soma translocation (Fig. $2 \mathrm{~B}$ ). This suggests that $\mathrm{F}$-actin dynamics in the leading tip rather than along the shaft is required for driving soma translocation. Surprisingly, local disruption of microtubules in the middle of the leading process with a low dose of its depolymerizing agent Noc (50 $\mu \mathrm{M}$ in the pipette) resulted in a transient increase in soma translocation speed (Fig. $3 B, E, F$ ), and this accelerated soma translocation was suppressed when LA was coapplied in the perfusion solution (Fig. 3D-F). In contrast, similar local perfusion with the microtubule stabilizing agent Taxol (100 $\mu \mathrm{M}$ in the pipette) impeded soma translocation (Fig. $3 E, F)$. These findings support the idea that $\mathrm{F}$-actin but not microtubules along the leading process is responsible for transmitting the traction force from the tip to soma.

In sharp contrast to that found by the perfusion of the leading process, local perfusion of LA, CD, or Jasp at the soma had no effect on soma translocation (Fig. $4 A, C, D$ ). However, soma translocation was facilitated by Noc but inhibited by local perfusion of Taxol at the soma (Fig. 4B-D). The lack of effect on soma translocation by LA and $\mathrm{CD}$ is consistent with the low level of F-actin at the soma (Fig. 2A). Notably, our results did not reveal
B
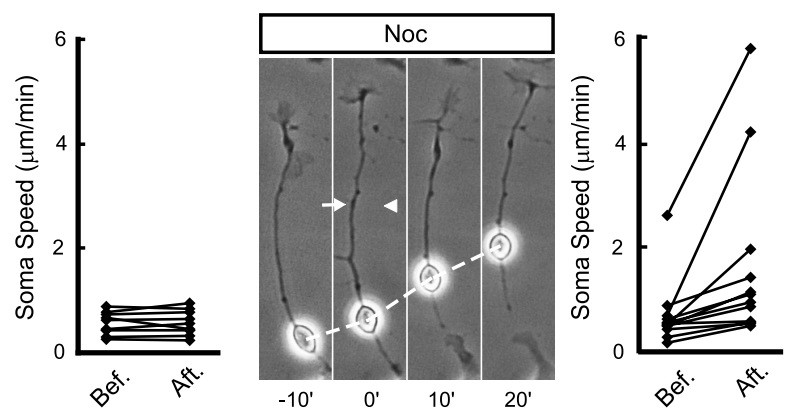

D
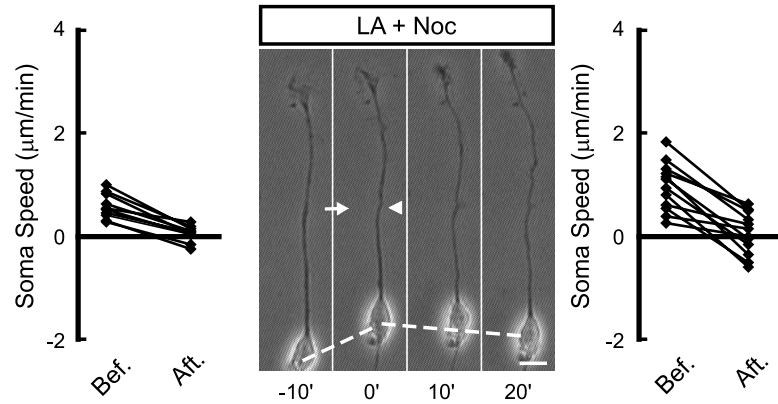

F

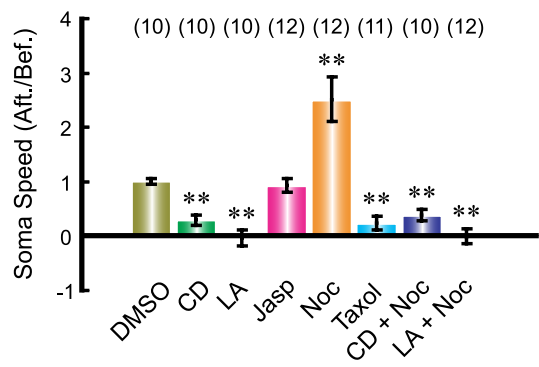

Figure 3. F-actin in the leading process shaft is essential for soma translocation. The leading processes of migrating neurons were locally perfused with indicated pharmacological agents. Representative images (left) with the speed of soma translocation before and after the perfusion (right) of each agent are shown in $\boldsymbol{A}-\boldsymbol{D}$. The arrows and arrowheads in images indicate the direction gical agents applied are DMSO ( $0.1 \%$ in the pipette), LA (100 $\mu \mathrm{m}$ in the pipette), CD (50 $\mu \mathrm{m}$ in the pipette), Jasp (5 $\mu \mathrm{m}$ in the treatment are shown in brackets. ${ }^{* *} p<0.01$, significant difference from the DMSO-treated group (Student's $t$ test and Kolmogorov-Smirnov test). Error bars, SEM. Scale bar, $10 \mu \mathrm{m}$.

a positive role for the microtubule in soma translocation in these cultured neurons. Rather, they supported the idea that microtubule bundles in the leading process may restrict soma advance during neuronal migration (Rakic et al., 1996). However, microtubules may contribute indirectly to neuronal migration by maintaining the polarized morphology of these migrating neurons, since prolonged disruption of microtubules in the leading process by Noc abolished neuronal polarity (supplemental Fig. 4, available at www.jneurosci.org as supplemental material) (see also Baudoin et al., 2008).

\section{F-actin flow in migrating neurons}

The above results showed that F-actin rather than microtubules in the leading process is essential for soma translocation. To further understand the action of F-actin, we used fluorescent speckle microscopy to analyze F-actin dynamics along the entire neuron. Cultured granule cells were transfected with GFP-tagged 
A
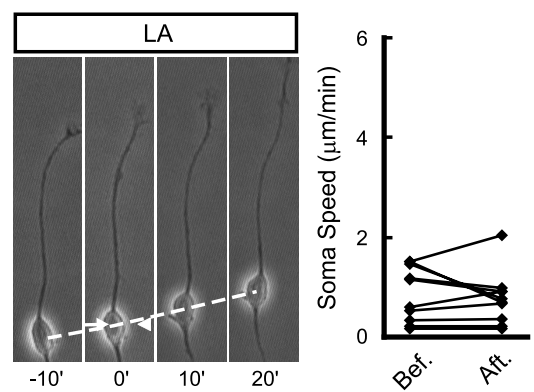

C

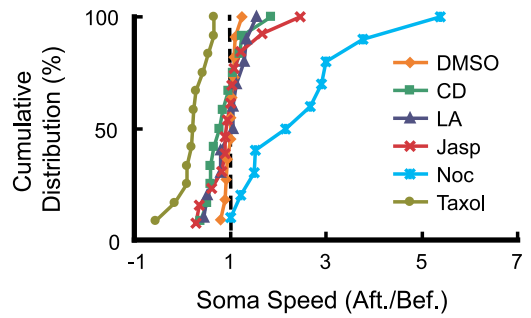

B
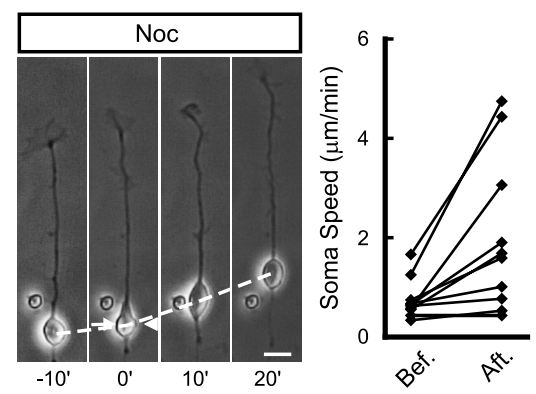

D

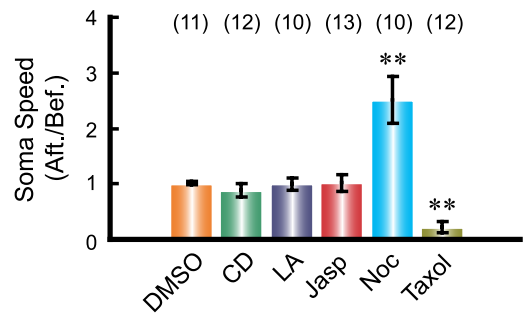

leading process (Fig. 5D; supplemental Movie 6, available at www.jneurosci.org as supplemental material).

To further test whether the soma advance is pulled by the forward F-actin flow, we prevented this flow by incubating the cells with Con A, a tetravalent lectin that immobilizes cortical F-actin by cross-linking cell surface glycoproteins (Tencer, 1978; Canman and Bement, 1997; Rosenblatt et al., 2004). We found that Con A treatment $(100 \mu \mathrm{g} / \mathrm{ml}$ in bath) totally prevented the F-actin flow along the shaft of the leading process without blocking the retrograde F-actin flow at the GC-like tip structure (Fig. 6A,D) and inhibited the soma advance without affecting the leading tip extension (Fig. 6E). This result is consistent with the idea that soma translocation depends directly on the force-transducing F-actin flow in the leading process but not the simple extension of the leading tip.

Figure 4. Effects of drug perfusion at neuronal soma. Different agents were locally applied to the neuronal soma with a pair of pipettes. Representative images (left) with average soma speed before and after application of indicated agents (right) are shown in $\boldsymbol{A}$ and $\boldsymbol{B}$. The normalized soma speed (after/before) of each cell under various treatments is shown in the cumulative distribution graph in $\boldsymbol{C}$, and the average soma speed (after/before) is shown in the histogram in $\boldsymbol{D}$. Agents were used in the same concentration as in Figure 3. Numbers of the examined cells for each treatment are shown in brackets. ${ }^{* *} p<0.01$, significant difference from the DMSO-treated group (Student's $t$ test and Kolmogorov-Smirnov test). Error bars, SEM. Scale bar, $10 \mu \mathrm{m}$.

$\alpha$-actinin, an F-actin-associated protein commonly used as the marker of F-actin (Giannone et al., 2007; Hu et al., 2007). The fluorescent $\alpha$-actinin speckles were found at the GC-like structure at the neurite tip, neurite shaft, and soma, colocalizing with phalloidin-labeled F-actin (supplemental Fig. 5A, available at www.jneurosci.org as supplemental material). Consistent with previous observations in axonal GCs (Medeiros et al., 2006), time-lapse imaging and kymographs derived from line scan at the GC-like structure showed continuous retrograde flow of fluorescent speckles from the periphery to the center (supplemental Fig. $5 B$, available at www.jneurosci.org as supplemental material). Interestingly, we observed a forward flow of fluorescent speckles along the leading process of migrating neurons (Fig. $5 A$, $E$; supplemental Movie 3, available at www.jneurosci.org as supplemental material), with the speed of flow correlated with that of soma translocation (Fig. $5 F$ ). In contrast, in nonmigrating neurons, we found that the neurite shaft exhibit either a retrograde flow of fluorescent speckles or stationary speckles (Fig. $5 B, E$ ), no matter whether the neurite was undergoing retraction (supplemental Fig. $6 A$, available at www.jneurosci.org as supplemental material) or not (Fig. 5B; supplemental Movie 4, available at www.jneurosci.org as supplemental material). As shown by the example in Figure $5 C$, a neuron that gained soma motility during the period of observation exhibited concurrent initiation of the F-actin flow in the shaft of the leading process (supplemental Movie 5, available at www.jneurosci.org as supplemental material). In contrast, when a migrating neuron exhibited gradual collapse of the leading tip and slowing of the soma advance, there was a corresponding reduction in the speed of forward F-actin flow (supplemental Fig. 6B, available at www.jneurosci.org as supplemental material). Furthermore, in a neuron undergoing spontaneous reversal of soma translocation, there was a correlated reversal of the F-actin flow in the original and newly formed

\section{Front-to-rear difference in myosin II activity is required for soma translocation}

The cortical F-actin flow is mainly driven by asymmetric contraction of actomyosin in animal cells (Bray and White, 1988; Munro et al., 2004). We found that in these cultured cerebellar granule cells, F-actin flow in the neurite shaft and the GC-like structured at the leading tip, either forward or retrograde, was totally abolished by bath application of the myosin II inhibitor BDM (20 mM in bath) or Bleb (50 $\mu \mathrm{M}$ in bath) (Fig. 6B-D). Importantly, these agents also suppressed the soma translocation (Fig. 6 F). Thus, myosin II may drive soma translocation via forward F-actin flow in the leading process.

How is the direction of F-actin flow in the leading process determined in migrating neurons? Since the cortical F-actin is known to flow toward the region of the higher actomyosin contractility (White and Borisy, 1983; Bray and White, 1988; Benink et al., 2000; Munro et al., 2004), we compared the actomyosin activity in migrating versus nonmigrating neurons by immunostaining of p-MLC(serine-19), which marks the activated form of myosin II. Neurons were first assayed for their migratory state with time-lapse video microscopy, fixed immediately and immunostained for $\mathrm{p}-\mathrm{MLC}$. The relative cytoplasmic level of $\mathrm{p}-\mathrm{MLC}$ was quantified by $\mathrm{p}-\mathrm{MLC}$ signal normalized by the signal of a cell volume marker CY3-Bis NHS Ester, which binds to all cytosolic proteins (Fig. $7 A, B$ ). We found that the average level of p-MLC in migrating neurons was higher than that of nonmigrating neurons (Fig. $7 C$ ). The average p-MLC levels measured at the tip region was consistently higher than that at the soma of migrating (but not nonmigrating) neurons (Fig. 7D). This distribution of p-MLC in migrating neurons, together with the observation of high F-actin level in the leading tip, supports the notion that the leading tip represents the region of the highest actomyosin activity in migrating neurons, thus is likely to be the site for initiating the traction force required for the forward F-actin flow in the leading process.

We next tested whether soma advance depends on the frontto-rear difference in the myosin II activity. We found that local application of the myosin II inhibitor, either Bleb or BDM, in 
A

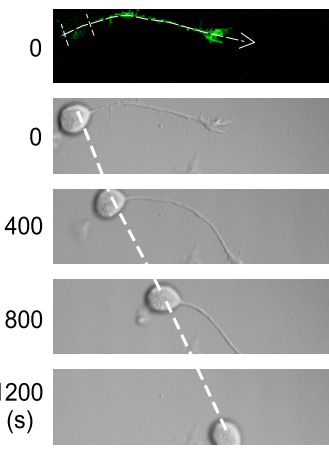

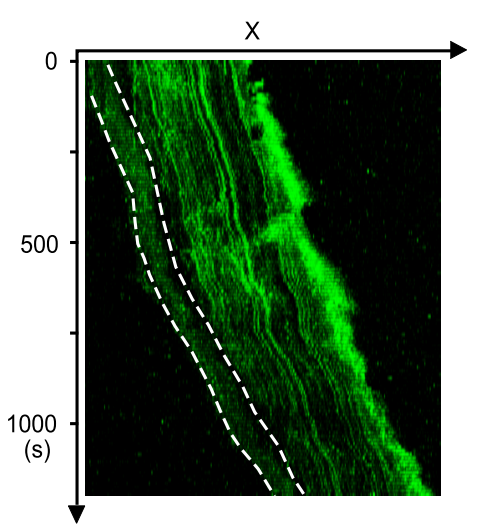

B

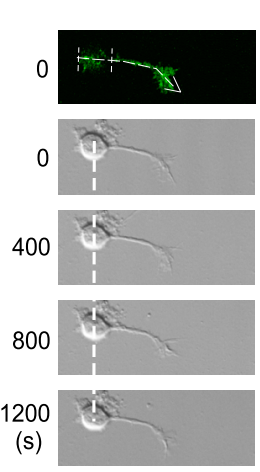

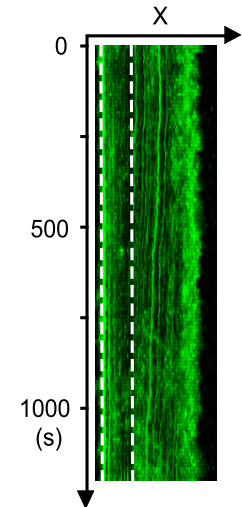

$\mathrm{X}$
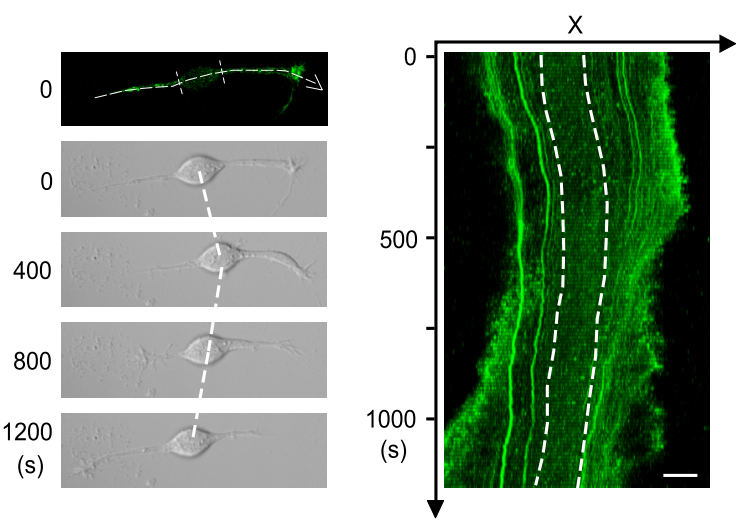

$\mathrm{E}$

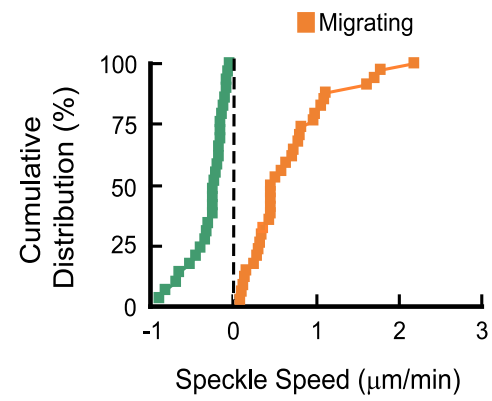

Non-migrating

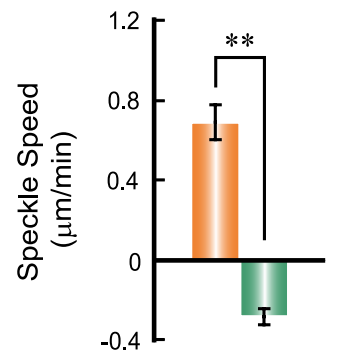

$\mathrm{F}$

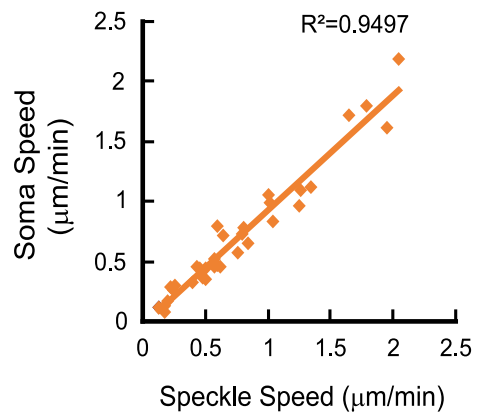

Figure 5. Soma translocation is correlated with a forward F-actin flow in the leading process. $\mathbf{A}-\boldsymbol{D}$, Time-lapse images (left) and kymographs (right) are shown to illustrate the F-actin flow in a migrating neuron $(\boldsymbol{A})$, a nonmigrating neuron $(\boldsymbol{B})$, a neuron that gained soma motility during the period of observation $(\boldsymbol{C})$, and a neuron undergoing spontaneous reversal of soma translocation $(\boldsymbol{D})$. Dashed lines in the fluorescent images represent the scan lines and arrows indicate the direction to generate kymographs. Two parallel dashed lines in each fluorescent image and kymograph mark the position of neuronal soma during the imaging. Note the retrograde flow of fluorescent speckles in the neurite of the nonmigrating neuron ( $\boldsymbol{B}$; see also supplemental Movie 4 , available at www.jneurosci.org as supplemental material), and a flow of speckles in the direction of soma translocation (A, C, $\boldsymbol{D}$; see also supplemental Movies 3, 5, 6, available at www.jneurosci.org as supplemental material). Scale bar, $10 \mu \mathrm{m}$. Cumulative distribution of the flow speed in migrating $(n=34)$ and nonmigrating neurons $(n=29)$ and average flow speed are shown in $E$. Error bar, SEM. The correlation between the speed of speckle flow and that of soma translocation is shown in $\boldsymbol{F}$. Each point in $\boldsymbol{E}$ and $\boldsymbol{F}$ represents a datum from one neuron, and only data from migrating neurons are included in $\boldsymbol{F}$.

front of the leading tip quickly impeded soma translocation (Fig. $8 A, E, G)$, whereas application of the same inhibitor at the rear of the soma accelerated soma advance (Fig. $8 B, F, H$ ). Similarly, frontal application the specific Rho kinase inhibitor Y-27632 (1 $\mathrm{mM}$ in the pipette) at the leading tip also significantly suppressed the soma translocation (Fig. $8 E, G$ ). Given that RhoA is one of the major upstream activators of the myosin II activity (Kimura et al., 1996; Matsumura, 2005), these results support the notion that soma translocation requires a front-to-rear difference in the myosin II activity. Finally, we tested whether changes in the frontto-rear difference of myosin II activity is sufficient to modulate soma translocation. We found that frontal application of the phosphatase inhibitor Caly ( $25 \mathrm{~nm}$ in the pipette) or Tau ( $1 \mu \mathrm{M}$ in the pipette), which activate myosin II by keeping the myosin regulatory light chain phosphorylated (Hori et al., 1991; Vallotton et al., 2004; Solecki et al., 2009), resulted in accelerated soma translocation (Fig. $8 C, E, G$ ), whereas rear application of these drugs had opposite effects (Fig. $8 D, F, H$ ). Thus, the front-to-rear difference in myosin II activity plays a key role in driving the soma translocation in migrating neurons.

\section{Discussion}

As a physically integrated cellular process (Lauffenburger and Horwitz, 1996), cell migration is generally preceded by protrusion of the leading edge (Pollard and Borisy, 2003). Immediately behind the leading edge, contraction of actomyosin and interac- 
A

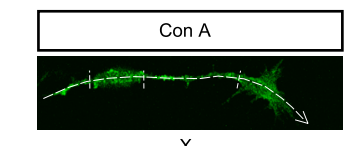

$\mathrm{X}$

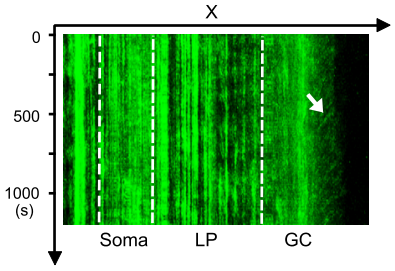

C

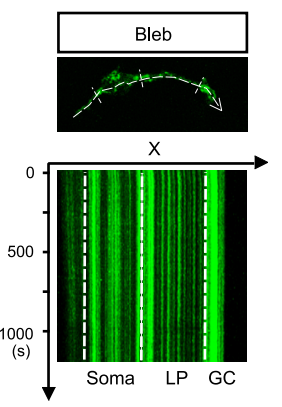

D ${ }_{100}$

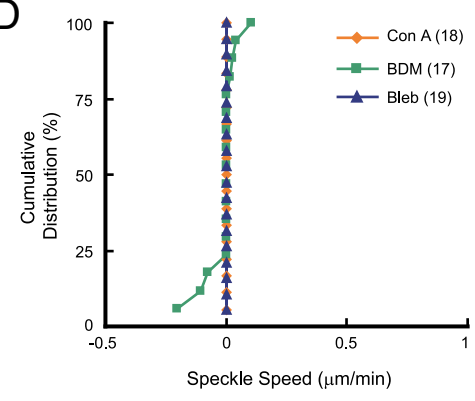

E

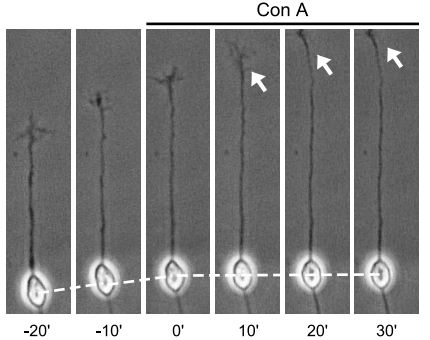

$\mathrm{F}$

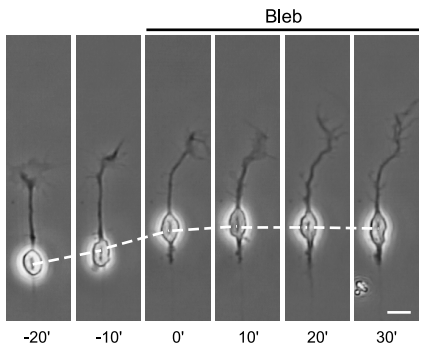

B
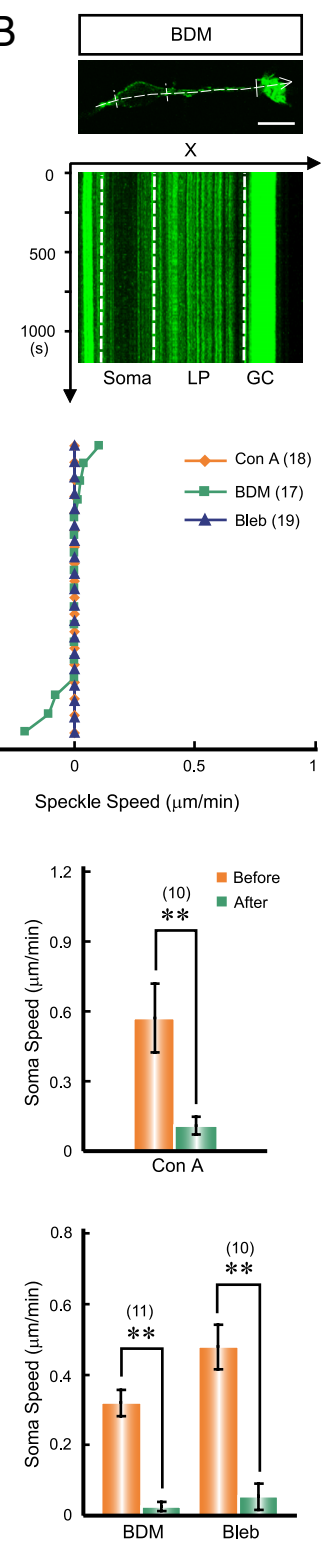

Figure 6. Myosin-II-dependent F-actin flow is required for soma translocation. $A-C$, Representative images and kymographs show the blockade of the $F$-actin flow in the leading process by bath application of Con A ( $A, 100 \mu \mathrm{g} / \mathrm{ml}$ in bath), BDM (B,20 mm in bath), or Bleb (C,50 $\mu \mathrm{M}$ in bath). Note that the retrograde flow of F-actin at the $\mathrm{GC}$-like tip structure was not blocked by Con $A$ treatment $(\boldsymbol{A}$, arrow). Dashed lines with an arrow in the fluorescent images represent the scan lines to generate the kymographs. The regions between parallel dashed lines in each fluorescent image and kymograph correspond to the position of soma, shaft of leading process $(\mathrm{LP})$, and the GC-like leading tip (GC). D, Cumulative distribution graphs show the blockade of F-actin flow in the leading process shaft by these agents. Each point in the graph represents datum from one neuron under different treatments. $\boldsymbol{E}, \boldsymbol{F}$, Soma translocation was blocked by bath application of Con $A(\boldsymbol{E})$, BDM or Bleb $(\boldsymbol{F})$. Arrows in $\boldsymbol{E}$ point to the actively extending $\mathrm{GC}-$ like tip structure. ${ }^{* *} p<0.01$, significant difference in soma speed before and after the drug application (Student's $t$ test). Numbers of examined cells for each treatment are shown in brackets. Error bars, SEM. Scale bars, $10 \mu \mathrm{m}$.

tion between cell surface and the substrate provide the traction force for moving the cell forward (Lowery and Van Vactor, 2009). Migrating neurons differ from other motile cells by having a long leading process, which connects the leading edge with the soma. In developing brain, many migrating neurons exhibit a GC-like structure at the tip of the leading process (Lambert de Rouvroit and Goffinet, 2001), although the leading tip of glia-supported migrating neurons is not as elaborated as that of tangentially

migrating neurons (Rakic, 1971; Rakic and Komuro, 1995). Besides sensing extracellular guidance cues like axonal growth cones (Lambert de Rouvroit and Goffinet, 2001; Marillat et al., 2004; Guan et al., 2007), the exact role of the GC-like leading tip in the traction of neuronal migration is not fully understood. Most previous studies relied on bath treatment of pharmacological agents and overexpression of mutant proteins to dissect the molecular mechanisms underlying the traction of neuronal migration. These manipulations interfered with cytoskeletal elements and signaling molecules either globally or chronically, and thus could not reveal the contribution of different cellular regions during neuronal migration. In this study, we used local perfusion of pharmacological agents in dissociated culture of migrating neurons to dissect the role of different cellular regions and cytoskeletal components in the traction of neuronal migration. We found that the GC-like leading tip is the structure that generates the traction force for soma translocation, in a manner similar to the traction exerted by the leading edge on several types of nonneuronal cells, e.g., fibroblasts (Munevar et al., 2001) and keratocytes (Galbraith and Sheetz, 1999). Such a GC-traction mechanism may be used during in vivo migration of those neurons bearing a prominent GC-like structure at the distal leading process, including interneurons undergoing tangential migration in the forebrain (Polleux et al., 2002; Bellion et al., 2005), inferior olivary neurons undergoing circumferential migration from the rhombic lip around the brainstem (Bourrat and Sotelo, 1988), and granule cells undergoing subpial migration from the rhombic lip over the cerebellar cortex (Hatten, 1999).

Myosin II has been identified recently as a key player in neuronal migration (Schaar and McConnell, 2005; Tsai et al., 2007; Vallee et al., 2009). Mutation of myosin heavy chain IIB (NMHC IIB) in mice results in severe retardation in neuronal migration of distinct groups of neurons (Ma et al., 2004). For radial migration of cortical neurons (Tsai et al., 2007) and tangential migration of interneurons in brain slices (Bellion et al., 2005), and for subventricular zone-derived neural progenitor cells migrating in a threedimensional matrix (Schaar and McConnell, 2005), myosin II was found to promote cell migration by generating contraction at the cell's rear end. However, a recent study reported that in gliasupported migration of cultured cerebellar granule cells, myosin II is enriched in the proximal region of the leading process, and is responsible for the coordinated motility of the centrosome and soma (Solecki et al., 2009). In the present work, we further showed that myosin II activity in the leading tip is primarily responsible for generating the traction force along the leading process that drives the forward translocation of the soma. Consistent with what was found in neurons migrating along the glial fibers (Solecki et al., 2009), we also observed a forward flow of F-actin from the proximal to distal leading process in spontaneously migrating neurons free of glial cells and demonstrated that such F-actin flow is required for the forward soma translocation. Furthermore, we observed a significant difference of myosin II activity between the leading tip and the soma in migrating neurons, indicating higher actomyosin contractility at the leading tip, as reflected also by the higher dynamics of the GC-like tip structure in migrating neurons. Since cortical actomyosin network is known to flow toward the region with higher cortical tension in animal cells (White and Borisy, 1983; Bray and White, 1988; Benink et al., 2000; Munro et al., 2004), we propose that the front-to-rear difference in actomyosin activity is responsible for driving the forward $\mathrm{F}$-actin flow along the leading process, which in turn pulls the soma forward. We observed that soma translocation was accelerated and impeded when myosin II activity was 
A

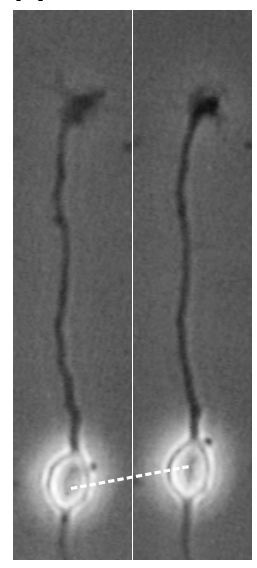

$0^{\prime}$

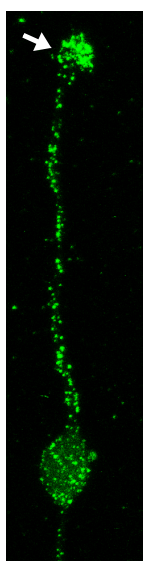

p-MLC

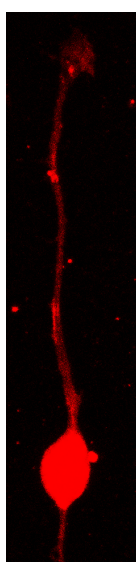

CY3

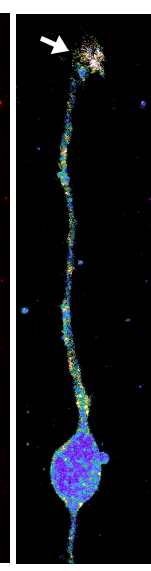

Ratio
B

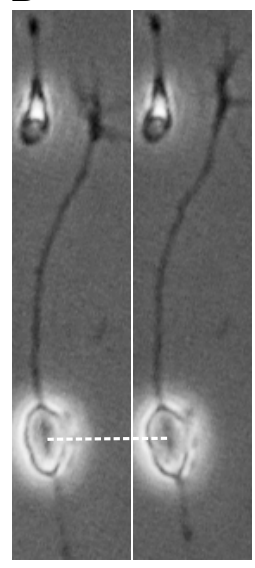

$0^{\prime}$

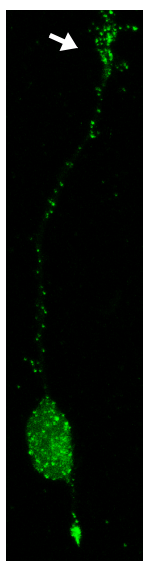

p-MLC

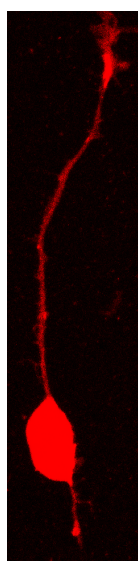

CY3

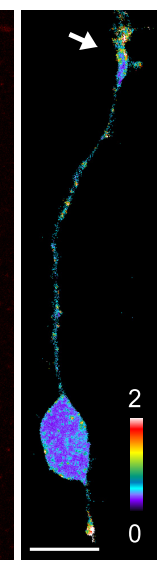

Ratio

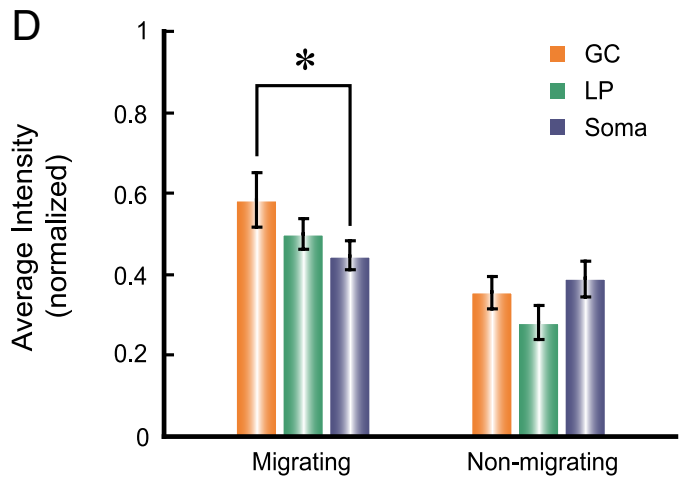

Figure 7. A front-high and back-low distribution of myosin Il activity exists in migrating neurons. $A, B$, Representative images show the distribution of phosphor-MLC (p-MLC) in a migrating ( $A$ ) and a nonmigrating ( $\boldsymbol{B})$ neuron. The relative cytoplasmic level of p-MLC (green) was normalized by the staining for a cell volume marker CY3-Bis NHS Ester (red) and coded by pseudocolors ( 0 -2). The average $\mathrm{p}-\mathrm{MLC}$ signals in the whole cell of migrating $(n=11)$ and nonmigrating $(n=11)$ neurons are shown in $C$. Average levels of $\mathrm{p}-\mathrm{MLC}$ in the $\mathrm{GC}-$ like tip structure (GC), shaft of the leading process (LP), and the soma of migrating and nonmigrating neurons are shown in $\boldsymbol{D}$. Note the gradual reduction of $p-M L C$ level from $G C$ to soma and the significant difference between $G C$ and soma in migrating neurons but not in nonmigrating neurons. ${ }^{*} p<0.05$, significant difference (Student's $t$ test). Error bars, SEM. Scale bar, $10 \mu \mathrm{m}$.

elevated and inhibited at the front, respectively, whereas these manipulations at the rear end of the migrating neuron resulted in opposite effects. These results support the model that soma translocation is "pulled" from the front rather than "pushed" from the cell rear during neuronal migration.

In many cell types, myosin II-driven flow of cortical F-actin could propel cell locomotion, GC migration, cytokinesis, and transport of signaling molecules (Bray and White, 1988). This myosin II-dependent $\mathrm{F}$-actin flow is also required for centrosome separation and positioning during mitotic spindle assembly (Rosenblatt et al., 2004), and for nucleus translocation in polarized cells (Gomes et al., 2005; Schenk et al., 2009). In the case of cultured fibroblasts at the wound-edge, rearward nuclear movement was coupled with a retrograde flow of F-actin and depended on myosin II activity (Gomes et al., 2005). Thus, the myosin II-driven F-actin flow may be general mechanism underlying polarized cell motility. Whether and how the nucleus, centrosome, and other intracellular organelles within the soma are directly associated with the cortical F-actin network during neuronal migration remains to be clarified.

A recent study of the radial migration of embryonic serotonergic neurons in a slice culture preparation showed that soma translocation of these neurons was independent of myosin II, but depended on the microtubule-based motor protein dynamin (Hawthorne et al., 2010). It is likely that the proper migration of neurons in developing brain may involve the complementary and/or redundant function of multiple motor proteins (Bellion et al., 2005). In addition, since activities of motor proteins could be regulated by extracellular (Gomes et al., 2005) and intracellular signaling cascades (Gutjahr et al., 2005), specific type of motor proteins may be fully activated and play the dominant role in the traction of soma translocation under specific tissue environments, including various extracellular matrix components (Zhang et al., 2008), substrate stiffness (Gupton and WatermanStorer, 2006), and second messenger levels inside the cell.

Myosin II is known to be activated by the small GTPase RhoA. Recent time-lapse imaging of fluorescent biosensors showed in non-neuronal cells, RhoA activity is elevated at the leading edge during cell migration (Pertz et al., 2006), consistent with an active role of RhoA signaling in the leading edge protrusion and ruffling, as well as cell motility (Fukata et al., 1999; Palazzo et al., 2004; Kurokawa and Matsuda, 2005; Pertz et al., 2006; Machacek et al., 2009). Our previous study has shown a front-to-rear gradient of active RhoA in cultured cerebellar granule cells undergoing active migration (Guan et al., 2007), consistent with the present finding of higher myosin II activity at the leading tip. The suppression of soma translocation by a gradient of the Rho kinase inhibitor Y-27632 in front of the leading tip suggests that polarized RhoA activity may contribute to the front-to-rear difference in myosin II activity which generates the traction force for soma advance. The polarity protein complex $\mathrm{Par} 6 / \mathrm{PKC} \zeta$ is localized to the centrosome of migrating neurons and plays an essential role 
A

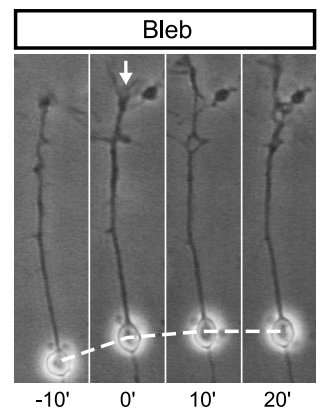

C

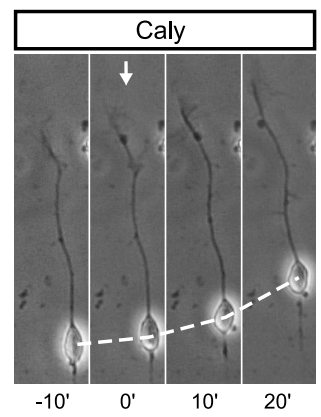

E

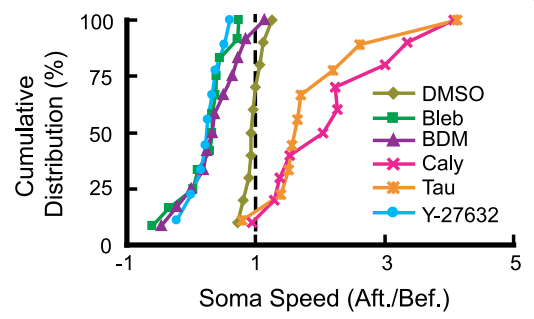

G
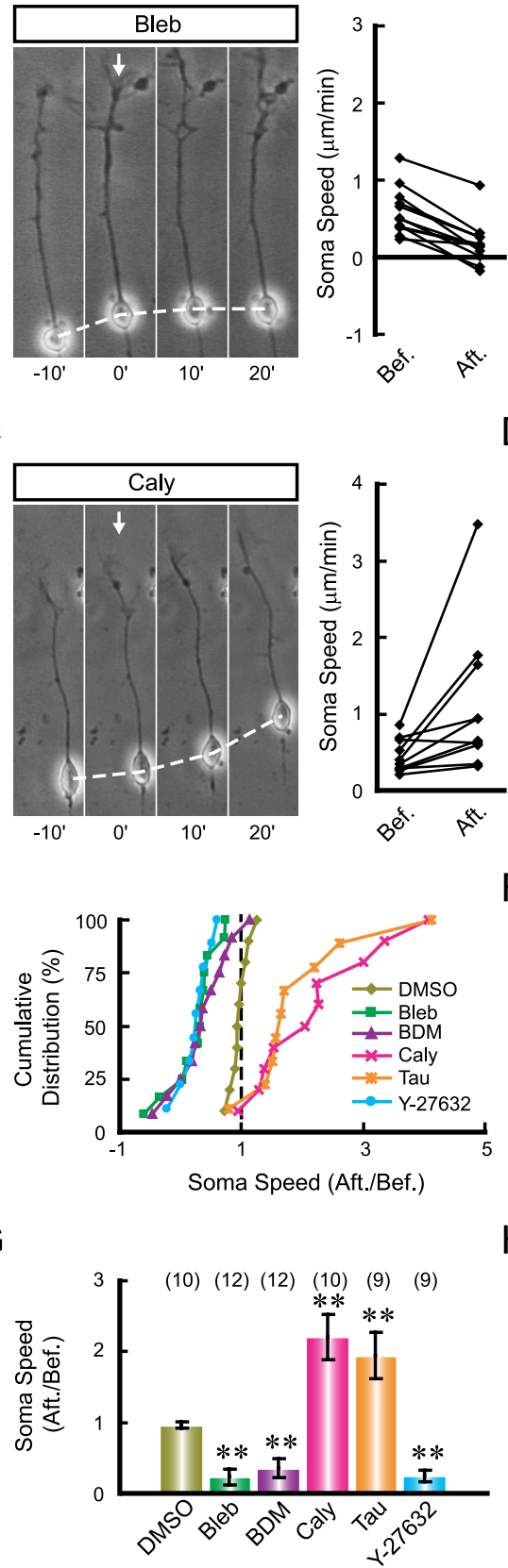

B
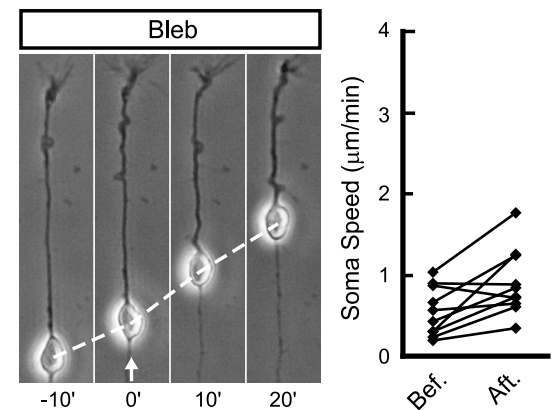

D
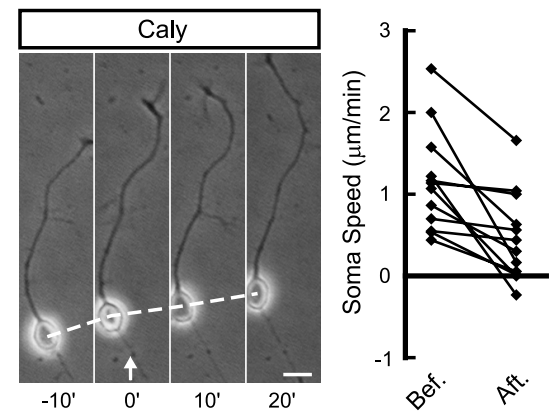

$\mathrm{F}$

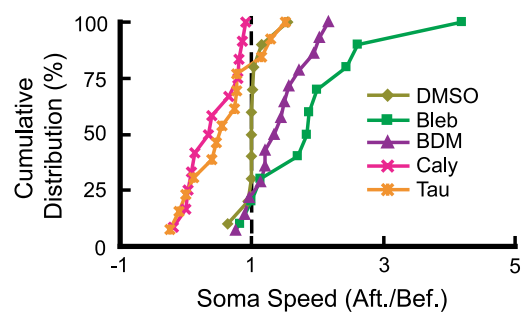

$\mathrm{H}$

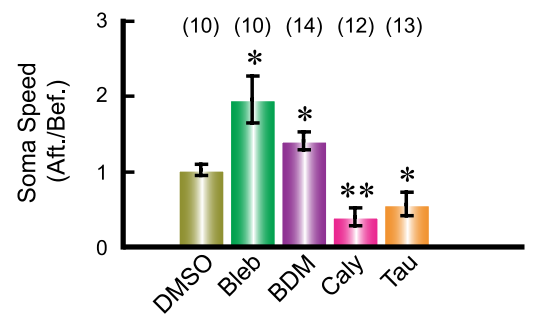

Figure 8. Front-high and back-low distribution of myosin II activity is essential for soma translocation. $A-D$, Neurons were exposed to a gradient of myosin II inhibitors $(\boldsymbol{A}, \boldsymbol{B})$ or activators $(\boldsymbol{C}, \boldsymbol{D})$, either from the front $(\boldsymbol{A}, \boldsymbol{C})$ or from the rear end $(\boldsymbol{B}, \boldsymbol{D})$. Arrows indicate the direction of drug application. The normalized soma speed (after/before) of cells under various treatments are shown in the cumulative distribution graphs in $\boldsymbol{E}$ (frontal application experiments) and $\boldsymbol{G}$ (rear application experiments), and the average soma speed (after/before) is shown in the histogram in $\boldsymbol{F}$ (frontal application of agents) and $\boldsymbol{H}$ (rear application of agents). Pharmacological agents applied are DMSO ( $0.1 \%$ in the pipette), Bleb ( $5 \mathrm{~mm}$ in the pipette), BDM ( $200 \mathrm{~mm}$ in the pipette), Caly ( 25 nm in the pipette), Tau (1 $\mu \mathrm{m}$ in the pipette), Y-27632 (1 mm in the pipette). Numbers of examined cells for each treatment are shown in brackets. ${ }^{*} p<0.05,{ }^{* *} p<0.01$, significant difference comparing with the DMSO-treated group (Student's $t$ test and Kolmogorov-Smirnov test). Error bars, SEM. Scale bar, $10 \mu \mathrm{m}$.

in the migration of granule cells on glial fibers (Solecki et al., 2004, 2009). Interestingly, Par6 negatively regulates the RhoA signaling pathway and inhibits the phosphorylation of MLC (Zhang and Macara, 2008; Solecki et al., 2009). Thus, Par6 at the centrosome may further promote soma advance by enhancing front-to-rear difference in myosin II activity via suppressing somatic RhoA and myosin II activities.
Microtubule-dependent motor proteins are known to generate the traction force for the movement of the centrosome and nucleus (Tanaka et al., 2004; Tsai and Gleeson, 2005; Tsai et al., 2007). During radial migration of cortical neurons, activities of both dynein and myosin II are necessary for nuclear movement (Tsai et al., 2007), and synergistic actions of these motor proteins may occur via close interaction of the dynein/microtubule complexes with the cortical F-actin network (Dujardin and Vallee, 2002; Dujardin et al., 2003). The microtubule-associated proteins doublecortin (DCX) and MARK2 are also essential in neuronal migration (Gleeson et al., 1998, 1999; Sapir et al., 2008a,b), and their actions may be mediated by regulation of the stability of both microtubules and F-actin (Matenia et al., 2005; Tsukada et al., 2005; Tint et al., 2009), leading to coordinated motility of the leading tip and soma. Whether and how microtubule-based motility are involved in regulating the traction force for soma translocation in our present system of cultured granule cells remains to be further investigated.

In addition to the role of microtubules in nucleokinesis, it has been proposed that the rigid microtubule bundles inside the leading process may prevent nucleus advance and soma translocation may require the disassembly of microtubule bundles at the proximal segment of the leading process (Rakic et al., 1996). Our study provides direct experimental support for this idea. We found that neuronal migration was impeded by stabilizing and accelerated by disrupting microtubules in the leading process and the soma. Consistent with this notion, induction of microtubule bundling correlated with impediment of neuronal migration in developing cortex (de Nijs et al., 2009). In non-neuronal cells, proper cell migration requires microtubule severing at the minus end and the release of microtubules from the centrosome (Abal et al., 2002; Toyo-Oka et al., 2005; Sudo and Maru, 2008), processes that may help to remove the restriction of microtubule arrays on nucleus advance. Moreover, pharmacological disruption of microtubules increases F-actin-mediated contractility in many different cell types, including PC12 cells (Dennerll et al., 1988), fibroblasts (Danowski, 1989), retinal photoreceptor cells (Madreperla and Adler, 1989), and cardiac muscle cells (Tsutsui et al., 1993). In Xenopus oocytes, cortical F-actin flow could be suppressed by microtubule polymerization and enhanced by microtubule depolymerization (Canman and Bement, 1997; Benink et al., 2000). In addition, disrupting microtubules in chicken embryonic fibroblast resulted in increased 
phosphorylation of MLC (Kolodney and Elson, 1995), an effect that may help to fuel the F-actin flow. These observations imply that restrictive effects of microtubules on neuronal migration may, at least in part, be attributed to their suppression on cortical F-actin flow. It is thus of interest to determine whether the known function of dynein motor complexes in driving the nucleokinesis is mediated by direct traction of the nucleus along microtubules or by promoting microtubule remodeling that releases the constraint on nuclear advance driven by F-actin flow, or both.

The extracellular matrix protein reelin promotes the radial migration and the inside-out laminar deployment of embryonic cortical neurons. Reelin mutant mouse (reeler mouse) exhibits severe neuronal migration defects and totally inversed cortical lamination (Hatten, 1999; Rice and Curran, 2001). A recent study showed that SUN-domain proteins SUN1 and SUN2 and the KASH-domain proteins Syne-1/Nesprin-1 and Syne-2/Nesprin-2s are directly involved in the soma translocation during neuronal migration by connecting nuclear envelop with microtubule-based motor proteins (Zhang et al., 2009). Mutations in these proteins result in inversion of cortical layers reminiscent of the characteristic migration defects in the well known reeler mutant, suggesting that reelin signaling is essential for the soma translocation in vivo. Reelin has been shown to stabilize the leading process of migrating neurons by triggering the phosphorylation and inactivation of the F-actin severing protein cofilin (Chai et al., 2009b, 2009a). Interestingly, reelin is enriched in the marginal zone of developing cortical plate, a layer that the tip of leading process of migrating neurons could reach. This suggests that the regulatory signal of reelin on neuronal soma translocation is mainly received by the tip of the leading process in developing cerebral cortex, consistent with our finding of an important role of the GC-like leading tip in soma translocation. Besides mutations in reelin signaling pathway, retardation in neuronal migration happens in many other pathological conditions, including a wide spectrum of developmental neurological disorders in humans (Hatten, 1999; Gleeson, 2001; Spalice et al., 2009). It is of great interest to explore whether migration retardation under these pathological conditions is caused by failure in the generation or transmission of the traction force by the GC-like leading tip in migrating neurons during development.

In summary, our work supports the following model of neuronal migration: The leading tip of migrating neurons pulls soma forward through a myosin II-dependent forward flow of F-actin along the leading process. Our finding of the leading tip as the force-generating structure for soma translocation offers new insight into the molecular machinery underlying the coordinated motility of the leading edge and soma during neuronal migration.

\section{References}

Abal M, Piel M, Bouckson-Castaing V, Mogensen M, Sibarita JB, Bornens M (2002) Microtubule release from the centrosome in migrating cells. J Cell Biol 159:731-737.

Baudoin JP, Alvarez C, Gaspar P, Métin C (2008) Nocodazole-induced changes in microtubule dynamics impair the morphology and directionality of migrating medial ganglionic eminence cells. Dev Neurosci 30:132-143.

Bellion A, Baudoin JP, Alvarez C, Bornens M, Métin C (2005) Nucleokinesis in tangentially migrating neurons comprises two alternating phases: forward migration of the Golgi/centrosome associated with centrosome splitting and myosin contraction at the rear. J Neurosci 25:5691-5699.

Benink HA, Mandato CA, Bement WM (2000) Analysis of cortical flow models in vivo. Mol Biol Cell 11:2553-2563.

Bourrat F, Sotelo C (1988) Migratory pathways and neuritic differentiation of inferior olivary neurons in the rat embryo. Axonal tracing study using the in vitro slab technique. Brain Res 467:19-37.
Bray D (1979) Mechanical tension produced by nerve cells in tissue culture. J Cell Sci 37:391-410.

Bray D, White JG (1988) Cortical flow in animal cells. Science 239:883-888. Canman JC, Bement WM (1997) Microtubules suppress actomyosin-based cortical flow in Xenopus oocytes. J Cell Sci 110:1907-1917.

Chai X, Förster E, Zhao S, Bock HH, Frotscher M (2009a) Reelin stabilizes the actin cytoskeleton of neuronal processes by inducing $\mathrm{n}$-cofilin phosphorylation at serine3. J Neurosci 29:288-299.

Chai X, Förster E, Zhao S, Bock HH, Frotscher M (2009b) Reelin acts as a stop signal for radially migrating neurons by inducing phosphorylation of $\mathrm{n}$-cofilin at the leading edge. Commun Integr Biol 2:375-377.

Danowski BA (1989) Fibroblast contractility and actin organization are stimulated by microtubule inhibitors. J Cell Sci 93:255-266.

de Nijs L, Léon C, Nguyen L, Loturco JJ, Delgado-Escueta AV, Grisar T, Lakaye B (2009) EFHC1 interacts with microtubules to regulate cell division and cortical development. Nat Neurosci 12:1266-1274.

Dennerll TJ, Joshi HC, Steel VL, Buxbaum RE, Heidemann SR (1988) Tension and compression in the cytoskeleton of PC-12 neurites. II: Quantitative measurements. J Cell Biol 107:665-674.

Ding S, Luo JH, Yuan XB (2007) Semaphorin-3F attracts the growth cone of cerebellar granule cells through cGMP signaling pathway. Biochem Biophys Res Commun 356:857-863.

Dujardin DL, Vallee RB (2002) Dynein at the cortex. Curr Opin Cell Biol 14:44-49.

Dujardin DL, Barnhart LE, Stehman SA, Gomes ER, Gundersen GG, Vallee RB (2003) A role for cytoplasmic dynein and LIS1 in directed cell movement. J Cell Biol 163:1205-1211.

Edmondson JC, Hatten ME (1987) Glial-guided granule neuron migration in vitro: a high-resolution time-lapse video microscopic study. J Neurosci 7:1928-1934.

Fletcher DA, Mullins RD (2010) Cell mechanics and the cytoskeleton. Nature 463:485-492.

Fukata Y, Oshiro N, Kinoshita N, Kawano Y, Matsuoka Y, Bennett V, Matsuura Y, Kaibuchi K (1999) Phosphorylation of adducin by Rho-kinase plays a crucial role in cell motility. J Cell Biol 145:347-361.

Galbraith CG, Sheetz MP (1999) Keratocytes pull with similar forces on their dorsal and ventral surfaces. J Cell Biol 147:1313-1324.

Gallo G, Yee HF Jr, Letourneau PC (2002) Actin turnover is required to prevent axon retraction driven by endogenous actomyosin contractility. J Cell Biol 158:1219-1228.

Giannone G, Dubin-Thaler BJ, Rossier O, Cai Y, Chaga O, Jiang G, Beaver W, Döbereiner HG, Freund Y, Borisy G, Sheetz MP (2007) Lamellipodial actin mechanically links myosin activity with adhesion-site formation. Cell 128:561-575.

Gleeson JG (2001) Neuronal migration disorders. Ment Retard Dev Disabil Res Rev 7:167-171.

Gleeson JG, Allen KM, Fox JW, Lamperti ED, Berkovic S, Scheffer I, Cooper EC, Dobyns WB, Minnerath SR, Ross ME, Walsh CA (1998) Doublecortin, a brain-specific gene mutated in human X-linked lissencephaly and double cortex syndrome, encodes a putative signaling protein. Cell 92:63-72.

Gleeson JG, Lin PT, Flanagan LA, Walsh CA (1999) Doublecortin is a microtubule-associated protein and is expressed widely by migrating neurons. Neuron 23:257-271.

Gomes ER, Jani S, Gundersen GG (2005) Nuclear movement regulated by Cdc42, MRCK, myosin, and actin flow establishes MTOC polarization in migrating cells. Cell 121:451-463.

Guan CB, Xu HT, Jin M, Yuan XB, Poo MM (2007) Long-range Ca2+ signaling from growth cone to soma mediates reversal of neuronal migration induced by slit-2. Cell 129:385-395.

Gupton SL, Waterman-Storer CM (2006) Spatiotemporal feedback between actomyosin and focal-adhesion systems optimizes rapid cell migration. Cell 125:1361-1374.

Gutjahr MC, Rossy J, Niggli V (2005) Role of Rho, Rac, and Rho-kinase in phosphorylation of myosin light chain, development of polarity, and spontaneous migration of Walker 256 carcinosarcoma cells. Exp Cell Res 308:422-438.

Hatten ME (1999) Central nervous system neuronal migration. Annu Rev Neurosci 22:511-539.

Hawthorne AL, Wylie CJ, Landmesser LT, Deneris ES, Silver J (2010) Serotonergic neurons migrate radially through the neuroepithelium by dynamin-mediated somal translocation. J Neurosci 30:420-430. 
Heidemann SR, Buxbaum RE (1990) Tension as a regulator and integrator of axonal growth. Cell Motil Cytoskeleton 17:6-10.

Hori M, Magae J, Han YG, Hartshorne DJ, Karaki H (1991) A novel protein phosphatase inhibitor, tautomycin. Effect on smooth muscle. FEBS Lett 285:145-148.

Hu K, Ji L, Applegate KT, Danuser G, Waterman-Storer CM (2007) Differential transmission of actin motion within focal adhesions. Science 315:111-115.

Kimura K, Ito M, Amano M, Chihara K, Fukata Y, Nakafuku M, Yamamori B, Feng J, Nakano T, Okawa K, Iwamatsu A, Kaibuchi K (1996) Regulation of myosin phosphatase by Rho and Rho-associated kinase (Rho-kinase). Science 273:245-248.

Kolodney MS, Elson EL (1995) Contraction due to microtubule disruption is associated with increased phosphorylation of myosin regulatory light chain. Proc Natl Acad Sci U S A 92:10252-10256.

Komuro H, Rakic P (1995) Dynamics of granule cell migration: a confocal microscopic study in acute cerebellar slice preparations. J Neurosci 15:1110-1120.

Komuro H, Yacubova E, Yacubova E, Rakic P (2001) Mode and tempo of tangential cell migration in the cerebellar external granular layer. J Neurosci 21:527-540.

Kovács M, Tóth J, Hetényi C, Málnási-Csizmadia A, Sellers JR (2004) Mechanism of blebbistatin inhibition of myosin II. J Biol Chem 279:35557-35563.

Kurokawa K, Matsuda M (2005) Localized RhoA activation as a requirement for the induction of membrane ruffling. Mol Biol Cell 16:4294-4303.

Lambert de Rouvroit C, Goffinet AM (2001) Neuronal migration. Mech Dev 105:47-56.

Lamoureux P, Buxbaum RE, Heidemann SR (1989) Direct evidence that growth cones pull. Nature 340:159-162.

Lauffenburger DA, Horwitz AF (1996) Cell migration: a physically integrated molecular process. Cell 84:359-369.

Letourneau PC, Shattuck TA, Ressler AH (1987) "Pull" and "push" in neurite elongation: observations on the effects of different concentrations of cytochalasin B and taxol. Cell Motil Cytoskeleton 8:193-209.

Li Y, Jia YC, Cui K, Li N, Zheng ZY, Wang YZ, Yuan XB (2005) Essential role of TRPC channels in the guidance of nerve growth cones by brain-derived neurotrophic factor. Nature 434:894-898.

Lohof AM, Quillan M, Dan Y, Poo MM (1992) Asymmetric modulation of cytosolic cAMP activity induces growth cone turning. J Neurosci 12:1253-1261.

Lowery LA, Van Vactor D (2009) The trip of the tip: understanding the growth cone machinery. Nat Rev Mol Cell Biol 10:332-343.

Ma X, Kawamoto S, Hara Y, Adelstein RS (2004) A point mutation in the motor domain of nonmuscle myosin II-B impairs migration of distinct groups of neurons. Mol Biol Cell 15:2568-2579.

Machacek M, Hodgson L, Welch C, Elliott H, Pertz O, Nalbant P, Abell A, Johnson GL, Hahn KM, Danuser G (2009) Coordination of Rho GTPase activities during cell protrusion. Nature 461:99-103.

Madreperla SA, Adler R (1989) Opposing microtubule- and actindependent forces in the development and maintenance of structural polarity in retinal photoreceptors. Dev Biol 131:149-160.

Marillat V, Sabatier C, Failli V, Matsunaga E, Sotelo C, Tessier-Lavigne M, Chédotal A (2004) The slit receptor Rig-1/Robo3 controls midline crossing by hindbrain precerebellar neurons and axons. Neuron 43:69-79.

Matenia D, Griesshaber B, Li XY, Thiessen A, Johne C, Jiao J, Mandelkow E, Mandelkow EM (2005) PAK5 kinase is an inhibitor of MARK/Par-1, which leads to stable microtubules and dynamic actin. Mol Biol Cell $16: 4410-4422$.

Matsumura F (2005) Regulation of myosin II during cytokinesis in higher eukaryotes. Trends Cell Biol 15:371-377.

Medeiros NA, Burnette DT, Forscher P (2006) Myosin II functions in actinbundle turnover in neuronal growth cones. Nat Cell Biol 8:215-226.

Moore SW, Biais N, Sheetz MP (2009) Traction on immobilized netrin-1 is sufficient to reorient axons. Science 325:166.

Munevar S, Wang Y, Dembo M (2001) Traction force microscopy of migrating normal and $\mathrm{H}$-ras transformed $3 \mathrm{~T} 3$ fibroblasts. Biophys J 80:1744-1757.

Munro E, Nance J, Priess JR (2004) Cortical flows powered by asymmetrical contraction transport PAR proteins to establish and maintain anteriorposterior polarity in the early C. elegans embryo. Dev Cell 7:413-424.

O’Brien GS, Rieger S, Martin SM, Cavanaugh AM, Portera-Cailliau C, Sagasti A (2009) Two-photon axotomy and time-lapse confocal imaging in live zebrafish embryos. J Vis Exp 1129.

Ono K, Shokunbi T, Nagata I, Tokunaga A, Yasui Y, Nakatsuji N (1997) Filopodia and growth cones in the vertically migrating granule cells of the postnatal mouse cerebellum. Exp Brain Res 117:17-29.

Palazzo AF, Eng CH, Schlaepfer DD, Marcantonio EE, Gundersen GG (2004) Localized stabilization of microtubules by integrin- and FAKfacilitated Rho signaling. Science 303:836-839.

Pertz O, Hodgson L, Klemke RL, Hahn KM (2006) Spatiotemporal dynamics of RhoA activity in migrating cells. Nature 440:1069-1072.

Pollard TD, Borisy GG (2003) Cellular motility driven by assembly and disassembly of actin filaments. Cell 112:453-465.

Polleux F, Whitford KL, Dijkhuizen PA, Vitalis T, Ghosh A (2002) Control of cortical interneuron migration by neurotrophins and PI3-kinase signaling. Development 129:3147-3160.

Rakic P (1971) Neuron-glia relationship during granule cell migration in developing cerebellar cortex. A Golgi and electronmicroscopic study in Macacus Rhesus. J Comp Neurol 141:283-312.

Rakic P, Komuro H (1995) The role of receptor/channel activity in neuronal cell migration. J Neurobiol 26:299-315.

Rakic P, Knyihar-Csillik E, Csillik B (1996) Polarity of microtubule assemblies during neuronal cell migration. Proc Natl Acad Sci USA 93:9218-9222.

Rice DS, Curran T (2001) Role of the reelin signaling pathway in central nervous system development. Annu Rev Neurosci 24:1005-1039.

Ridley AJ, Schwartz MA, Burridge K, Firtel RA, Ginsberg MH, Borisy G, Parsons JT, Horwitz AR (2003) Cell migration: integrating signals from front to back. Science 302:1704-1709.

Rivas RJ, Hatten ME (1995) Motility and cytoskeletal organization of migrating cerebellar granule neurons. J Neurosci 15:981-989.

Rosenblatt J, Cramer LP, Baum B, McGee KM (2004) Myosin II-dependent cortical movement is required for centrosome separation and positioning during mitotic spindle assembly. Cell 117:361-372.

Sapir T, Shmueli A, Levy T, Timm T, Elbaum M, Mandelkow EM, Reiner O (2008a) Antagonistic effects of doublecortin and MARK2/Par-1 in the developing cerebral cortex. J Neurosci 28:13008-13013.

Sapir T, Sapoznik S, Levy T, Finkelshtein D, Shmueli A, Timm T, Mandelkow EM, Reiner O (2008b) Accurate balance of the polarity kinase MARK2/ Par-1 is required for proper cortical neuronal migration. J Neurosci 28:5710-5720.

Schaar BT, McConnell SK (2005) Cytoskeletal coordination during neuronal migration. Proc Natl Acad Sci U S A 102:13652-13657.

Schenk J, Wilsch-Bräuninger M, Calegari F, Huttner WB (2009) Myosin II is required for interkinetic nuclear migration of neural progenitors. Proc Natl Acad Sci U S A 106:16487-16492.

Solecki DJ, Model L, Gaetz J, Kapoor TM, Hatten ME (2004) Par6alpha signaling controls glial-guided neuronal migration. Nat Neurosci 7:1195-1203.

Solecki DJ, Govek EE, Hatten ME (2006) mPar6 alpha controls neuronal migration. J Neurosci 26:10624-10625.

Solecki DJ, Trivedi N, Govek EE, Kerekes RA, Gleason SS, Hatten ME (2009) Myosin II motors and F-actin dynamics drive the coordinated movement of the centrosome and soma during CNS glial-guided neuronal migration. Neuron 63:63-80.

Spalice A, Parisi P, Nicita F, Pizzardi G, Del Balzo F, Iannetti P (2009) Neuronal migration disorders: clinical, neuroradiologic and genetics aspects. Acta Paediatr 98:421-433.

Sudo H, Maru Y (2008) LAPSER1/LZTS2: a pluripotent tumor suppressor linked to the inhibition of katanin-mediated microtubule severing. Hum Mol Genet 17:2524-2540.

Suter DM, Forscher P (2000) Substrate-cytoskeletal coupling as a mechanism for the regulation of growth cone motility and guidance. J Neurobiol 44:97-113.

Tanaka T, Serneo FF, Higgins C, Gambello MJ, Wynshaw-Boris A, Gleeson JG (2004) Lis1 and doublecortin function with dynein to mediate coupling of the nucleus to the centrosome in neuronal migration. J Cell Biol 165:709-721.

Tencer R (1978) Transmembrane effects of lectins. I. Effects of wheat germ 
agglutinin and soybean agglutinin on furrow formation and cortical wound healing in Xenopus laevis eggs. Exp Cell Res 116:253-260.

Tint I, Jean D, Baas PW, Black MM (2009) Doublecortin associates with microtubules preferentially in regions of the axon displaying actin-rich protrusive structures. J Neurosci 29:10995-11010.

Toyo-Oka K, Sasaki S, Yano Y, Mori D, Kobayashi T, Toyoshima YY, Tokuoka SM, Ishii S, Shimizu T, Muramatsu M, Hiraiwa N, Yoshiki A, Wynshaw-Boris A, Hirotsune S (2005) Recruitment of katanin p60 by phosphorylated NDEL1, an LIS1 interacting protein, is essential for mitotic cell division and neuronal migration. Hum Mol Genet 14:3113-3128.

Tsai JW, Bremner KH, Vallee RB (2007) Dual subcellular roles for LIS1 and dynein in radial neuronal migration in live brain tissue. Nat Neurosci 10:970-979.

Tsai LH, Gleeson JG (2005) Nucleokinesis in neuronal migration. Neuron 46:383-388.

Tsukada M, Prokscha A, Ungewickell E, Eichele G (2005) Doublecortin association with actin filaments is regulated by neurabin II. J Biol Chem 280:11361-11368.

Tsutsui H, Ishihara K, Cooper G 4th (1993) Cytoskeletal role in the contractile dysfunction of hypertrophied myocardium. Science 260:682-687.

Vallee RB, Seale GE, Tsai JW (2009) Emerging roles for myosin II and cytoplasmic dynein in migrating neurons and growth cones. Trends Cell Biol 19:347-355.

Vallotton P, Gupton SL, Waterman-Storer CM, Danuser G (2004) Simultaneous mapping of filamentous actin flow and turnover in migrating cells by quantitative fluorescent speckle microscopy. Proc Natl Acad Sci U S A 101:9660-9665.

Walsh CA, Goffinet AM (2000) Potential mechanisms of mutations that affect neuronal migration in man and mouse. Curr Opin Genet Dev $10: 270-274$.

White JG, Borisy GG (1983) On the mechanisms of cytokinesis in animal cells. J Theor Biol 101:289-316.

Yacubova E, Komuro H (2002) Intrinsic program for migration of cerebellar granule cells in vitro. J Neurosci 22:5966-5981.

Yam PT, Wilson CA, Ji L, Hebert B, Barnhart EL, Dye NA, Wiseman PW, Danuser G, Theriot JA (2007) Actin-myosin network reorganization breaks symmetry at the cell rear to spontaneously initiate polarized cell motility. J Cell Biol 178:1207-1221.

Zhang H, Macara IG (2008) The PAR-6 polarity protein regulates dendritic spine morphogenesis through p190 RhoGAP and the Rho GTPase. Dev Cell 14:216-226.

Zhang X, Jiang G, Cai Y, Monkley SJ, Critchley DR, Sheetz MP (2008) Talin depletion reveals independence of initial cell spreading from integrin activation and traction. Nat Cell Biol 10:1062-1068.

Zhang X, Lei K, Yuan X, Wu X, Zhuang Y, Xu T, Xu R, Han M (2009) SUN1/2 and Syne/Nesprin-1/2 complexes connect centrosome to the nucleus during neurogenesis and neuronal migration in mice. Neuron 64:173-187.

Zheng JQ, Zheng Z, Poo M (1994) Long-range signaling in growing neurons after local elevation of cyclic AMP-dependent activity. J Cell Biol 127: 1693-1701. 